\title{
An Economy-Wide Evaluation of New Power Generation in South Africa: The Case of Medupi and Kusile
}

Bohlmann, J.A., Bohlmann, H.R., Inglesi-Lotz, R. and Van Heerden, J.H.

First Submitted July 2015

Revised June 2016

\begin{abstract}
This paper investigates the role that the building of two new power stations, Medupi and Kusile, will play in facilitating future economic activity in South Africa. We use a dynamic computable general equilibrium (CGE) model to estimate the economy-wide effects of these new power stations. Our simulation results also provide insight into how much the local economy has lost due to inadequate electricity supply in the period leading up to the construction of Medupi and Kusile. We find that the decision to build additional power generation capacity was necessary and justified, and that the failure to sooner recognise the need for expansion of the country's electricity generation capacity and subsequent delays in commissioning Medupi and Kusile, likely cost the economy over R110bn in lost production. Additional analysis, in which a further two-year delay in the construction of Medupi and Kusile is simulated, shows that such an event will cause the economy to perform below baseline projections up to 2022.
\end{abstract}

JEL Codes: C68, Q41, Q43

Keywords: Computable general equilibrium, UPGEM, electricity supply 


\section{Introduction}

The electricity grid in South Africa has been under severe pressure in recent years. The local economy has faced an on-going electricity crisis since the first series of regular blackouts and load shedding occurred in 2008. Diminished electricity reserve margins, brought on by a steady increase in demand relative to a stagnant supply, have left the country's electricity sector in desperate need of expansion in order to prevent further catastrophe. Recognising the looming crisis, Eskom ${ }^{1}$ and the Department of Energy launched the New Build Programme in $2005^{2}$ which has since been absorbed into the more comprehensive Integrated Resource Plan (IRP) (DoE, 2011; 2013). The key medium term outcome of the New Build Programme was the construction of two new coal-fired power stations, Medupi and Kusile, with a generation capacity of around 4800 MW each (Eskom, 2007; Eskom, 2010). With the long lag period that ensued between the planning and start of construction in late 2007, combined with various delays that have occurred during the construction phase, two major questions arise: 1) what will the contribution of Medupi and Kusile be in facilitating economic growth in South Africa going forward, assuming that both power stations will be brought online over the period 2014-2019, and 2) what has the lack of adequate electricity supply during the period 2008-2013 cost the South African economy? We also consider a third question: how would a delay in the construction of both power stations affect economic growth in the short run.

\footnotetext{
${ }^{1}$ Eskom is a state-owned enterprise responsible for around 95 per cent of grid-based electricity generation and distribution in South Africa. See Figure 1 for a profile of Eskom's power generation-mix and installed capacity.

${ }^{2}$ See Appendix A for details on Eskom's New Build Programme.
} 
Figure 1: Eskom Power Generation Mix and Installed Capacity (2014)

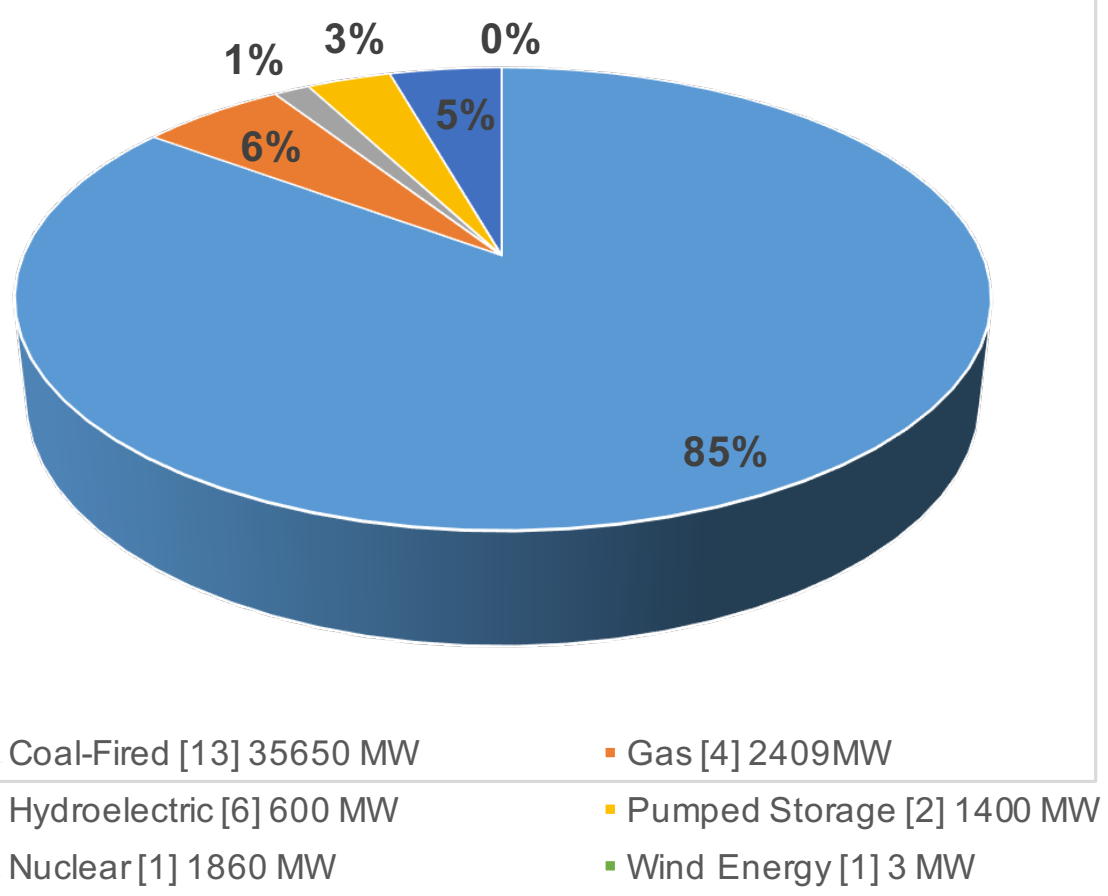

Source: Adapted from Eskom (2014c) 
In order to answer these empirical questions we use a dynamic computable general equilibrium (CGE) model of the South African economy. To measure and isolate the impact of Medupi and Kusile, we first run a hypothetical policy scenario in which the additional generation capacity scheduled to come online from these new power stations is eliminated, and compare this outcome to a baseline scenario in which Medupi and Kusile are brought online as scheduled. By interrogating the design and results of this policy simulation, we find that it also serves as a useful proxy to understanding how much the lack of adequate electricity supply since 2008 has cost the local economy, which some analysts have estimated to be as high as R300bn (Roodt, 2014). Our final policy scenario measures the impact of a two-year delay in the construction of Medupi and Kusile.

The remainder of the paper is structured as follows: Section 2 looks at some of the background and literature surrounding the electricity sector in South Africa. Section 3 describes the CGE methodology and model used in this paper. Section 4 details the design of the policy simulations and gives a careful analysis and interpretation of the results produced by the model. Section 5 concludes the study with a brief overview of the results and relevant policy implications.

\section{Background and Literature}

South Africa has historically been an energy-intensive economy ${ }^{3}$, particularly in terms of electricity usage by its industrial sector, consuming well above the world average MWh of electricity on a per capita basis (IEA, 2015). The reason why the industrial sector in South Africa is so energy-intensive can be traced back to the 1960s. During this period, South Africa experienced a boom in its mining and heavy metals industries, which led to significant increases in electricity demand. In

\footnotetext{
${ }^{3}$ Electricity forms the largest share of energy production and consumption in South Africa.
} 
response to the rapidly growing demand for electricity, Eskom built a large number of power stations in a short period of time (Etzinger, 2013). Additional supply was built to the extent that, during the 1980s and 1990s, electricity was in such oversupply that some power stations were mothballed and electricity sold at heavily subsidised rates to large industrial consumers. As may be expected, plans for the construction of additional electricity supply were not considered during this period. Many industries took advantage of the abundant supply of electricity at cheap and subsidised rates and entrenched itself in various electricity-intensive activities. In response to the growing dependence on cheap electricity for many of these industries, the Energy Intensive Users Group (EIUG) of South Africa, whose members account for over a third of electrical energy consumed in the country, was established in 1999. The EIUG membership comprises of large industries in the fields of mining, materials beneficiation and materials manufacturing. The group's main focus areas are to promote affordable and sustainable electricity prices and the security of electricity supply to its members and the country in general (EIUG, 2015). Indeed, the lobbying efforts of the EIUG, combined with long-term contracts, have ensured that many large industrial customers have continued to receive electricity at below, what Eskom considers, cost-reflective levels.

With abundant electricity supply still available during the 1990s, Eskom, the Department of Energy and policymakers were all lulled into a false sense of security regarding South Africa's future electricity infrastructure needs. Between 1994 and 2007, the South African economy grew much faster on average than it had in the previous two decades, which combined with many more households becoming connected to the grid during this period (The Presidency, 2014), quickly absorbed the excess electricity supply created during the 1960s and 1970s. By the time Eskom and other relevant policymakers concluded that new investment into electricity 
supply was required through the adoption of the New Build Programme in 2005, it was already too late to prevent the crisis that was to follow. When Koeberg, South Africa's only nuclear power station with a capacity of $1860 \mathrm{MW}$, first experienced major technical problems in late 2005 , it caused major disruptions to the electricity grid in the Western Cape where the plant is located. Subsequent instances of scheduled and unscheduled maintenance to Koeberg, as well as to other power stations around the country, exacerbated the problem. In early 2008, more technical and maintenance issues proved detrimental to the national electricity grid. With reserve margins depleted and Medupi and Kusile still years away from completion, these events ushered in an era of rolling blackouts and constrained economic activity.

In the wake of the 2008 electricity crisis, Eskom requested a series of aboveinflation tariff increases from the National Energy Regulator of South Africa (NERSA). Between the 2008/09 and 2012/13 financial years, the nominal price of electricity sold by Eskom increased by over 140 per cent (Eskom, 2015). Apart from improving Eskom's financial position and reducing its reliance on government subsidy, these large electricity price increases were also viewed as a demand-side management (DSM) strategy to help restore the balance between electricity demand and supply. Naturally, industry and consumer groups such as the EIUG protested against these rapid price increases, fearing that it might damage local firms' international competitiveness.

The combination of these events led to a surge in academic research studying the electricity sector in South Africa. Papers such as Alton et al. (2013) Blignaut (2012), Blignaut et al. (2015); Inglesi-Lotz \& Blignaut (2011; 2012a; 2012b; 2014); Inglesi \& Pouris (2010); Joubert (2015); Spalding-Fecher \& Khorommbi (2003); and Winkler (2007), amongst others, have made valuable contributions to the literature 
across a wide variety of electricity related topics. However, none of these papers used a comprehensive general equilibrium modelling framework to assess the economy-wide effects of Medupi and Kusile, specifically, whilst also measuring the cost of lost production due to inadequate supply in recent years, as we do in this paper.

\section{Methodology}

We use the University of Pretoria General Equilibrium Model (UPGEM) to conduct our analysis of the impact of Medupi and Kusile on the performance of the South African economy. UPGEM is a dynamic computable general equilibrium (CGE) model of South Africa. ${ }^{4}$ Its theoretical structure is based on the renowned MONASH model developed by the Centre of Policy Studies (CoPS) and documented in Dixon \& Rimmer (2002; 2005) and Dixon et al. (2013). The UPGEM database used in this paper is based on the 2011 supply-use (SU) tables published by Statistics South Africa. Following the mapping used in Bohlmann, H.R. et al. (2015), the database is aggregated to 25 sectors. ${ }^{5}$ As required for CoPS-style models, the initial levels solution of the model is provided by the base year data. The database, in combination with the model's theoretical specification, describes the main interlinkages in the economy. The theory of the model is then, essentially, a set of equations that describe how the values in the model's database move through time and move in response to any given shock. ${ }^{6}$

The ability of CGE models, such as UPGEM, to recognise the many real interlinkages in the economy, and account for price-induced behaviour and resource constraints in determining the economy-wide effects of a shock on the economy over

\footnotetext{
${ }^{4}$ This section borrows heavily from the description of UPGEM in Bohlmann, H.R. et al. (2015) where the same model and database were used.

${ }^{5}$ The electricity generation and distribution industry (SIC 41), under which the activities of Medupi and Kusile are captured, is recognised as one of the 25 industries in this aggregation of the UPGEM database.

${ }^{6}$ See Appendix B for a stylised representation of the model's core database.
} 
time, has made it one of the preferred methodologies for practical policy analysis around the world (Adams \& Parmenter, 2013). UPGEM is solved using the GEMPACK suite of programs described in Harrison \& Pearson (1996). GEMPACK eliminates linearisation errors by implementing shocks in a series of small steps and updating the database between steps.

Following the CoPS-style of implementing a CGE model, inspired by the pioneering work of Johansen (1960), the general equilibrium core of UPGEM is made up of a linearised system of equations describing the theory underlying the behaviour of participants in the economy. The specifications in UPGEM recognise each industry as producing one or more commodities, using as inputs combinations of domestic and imported commodities, different types of labour, capital and land. The multi-input, multi-output production specification is kept manageable by a series of separability assumptions, as illustrated in Appendix C. This nested production structure reduces the number of estimated parameters required by the model. Optimising equations determining the commodity composition of industry output are derived subject to a CET function, whilst functions determining industry inputs are determined by a series of CES nests. At the top level of this nesting structure intermediate commodity composites and a primary-factor composite are combined using a Leontief or fixed-proportions production function. Consequently, they are all demanded in direct proportion to industry output or activity. Each commodity composite is a CES function of a domestic good and its imported equivalent. This incorporates Armington's assumption of imperfect substitutability for goods by place of production (Armington, 1969).

The primary-factor composite is a CES aggregate of composite labour, capital and, in the case of primary sector industries, land. Composite labour demand is itself a CES aggregate of the different types of labour distinguished in the model's 
database. In UPGEM, all industries share this common production structure, but input proportions and behavioural parameters vary between industries based on base year data and available econometric estimates, respectively.

The demand and supply equations in UPGEM are derived from the solutions to the optimisation problems which are assumed to underlie the behaviour of private sector agents in conventional neo-classical microeconomics. Each industry minimises cost subject to given input prices and a constant returns to scale production function. Zero pure profits are assumed for all industries. Households maximise a Klein-Rubin utility function subject to their budget constraint. Units of new industry-specific capital are constructed as cost-minimising combinations of domestic and imported commodities. The export demand for any locally produced commodity is inversely related to its foreign-currency price. Government consumption, typically set exogenously in the baseline or linked to changes in household consumption in policy simulations, and the details of direct and indirect taxation are also recognised in the model.

The recursive-dynamic behaviour in UPGEM is specified through equations describing: physical capital accumulation; lagged adjustment processes in the labour market; and changes in the current account and net foreign liability positions. Capital accumulation is specified separately for each industry and linked to industryspecific net investment in the preceding period. Investment in each industry is positively related to its expected rate of return on capital, reflecting the price of capital rentals relative to the price of capital creation. For the government's fiscal accounts, a similar mechanism for financial asset/liability accumulation is specified. Changes in the public sector debt are related to the public sector debt incurred during a particular year and the interest payable on previous debt. Adjustments to the national net foreign liability position are related to the annual investment/savings 
imbalance, revaluations of assets and liabilities and remittance flows during the year. In policy simulations, the labour market follows a lagged adjustment path where wage rates respond over time to gaps between demand and supply for labour across each of the different occupation groups.

Dynamic CGE models such as UPGEM are designed to quantify the effects of a policy change, or exogenous shock, to the economy, over a period of time. We follow the standard CGE methodology described in Dixon et al. (2013) which determines that the best way to examine the effects of an exogenous shock is to compute the differences between a scenario in which the shock has occurred - the policy simulation - and a counterfactual scenario in which the particular shock under examination did not occur - the baseline scenario. ${ }^{7}$ Results are then reported as percentage change deviations over time between the first 'baseline' simulation run and the second 'policy' simulation run. For this paper, we use the standard baseline forecast and policy closures described in Dixon \& Rimmer (2002: 262-274). The nominal exchange rate is set as the numeraire in the policy run.

\section{Simulations}

\subsection{Baseline Forecast}

The baseline forecast is a necessary first step in order to conduct the policy simulation as it establishes a business-as-usual baseline path for the economy. Figures 2 and 3 show the main macro and industry level variables for which explicit

\footnotetext{
${ }^{7}$ We do a baseline forecast of the economy, change the closure of the model to the policy closure that will be used later in the policy simulation, and re-generate the baseline forecast with it. From here, we may now apply any set of additional policy shocks to the exogenous variables. If we would run a policy simulation where no additional shocks are applied to the policy variables, the original baseline forecast values would be the result of the simulation. This makes it legitimate to interpret differences between results in the policy and baseline runs as the effects of the policy shocks.
} 
non-zero forecast values were imposed over the simulation period up to and $2030 .^{8}$ Since the UPGEM database represents 2011 data, exogenous forecast values imposed for 2012-2014 represent available historical data, with 2015-2030 forecast values taken from National Treasury (2014) and CEPII (2013). Our baseline forecast includes a detailed projection of the expected growth in the country's overall electricity generation capacity up to 2030, including the new power generation scheduled to come online from Medupi and Kusile, as outlined in the IRP (DoE, 2013). Figure 2 shows the cumulative percentage changes, relative to 2011 , in the components of GDP from the expenditure side. Real GDP is expected to grow by 79.7 per cent up to 2030 , representing an average growth of 3.1 per cent over the 19-year forecast period. Figure 3 shows the cumulative percentage changes in electricity output and prices. In line with the IRP's SO Low Scenario (DoE, 2013:77), nominal electricity prices are expected to grow by 241.9 per cent and electricity generation capacity is expected to grow by 50.7 per cent over the forecast period.

\subsection{The Policy Scenarios}

The first policy scenario implemented in this paper is designed to isolate and measure the economy-wide contribution of new power generation, in the form of Medupi and Kusile. In order to do this, given the inclusion of Medupi and Kusile's additional generation capacity in the baseline, we run a counterfactual policy

\footnotetext{
${ }^{8}$ See Appendix D for results on selected macroeconomic and electricity sector variables in the baseline forecast simulation. In table D.1 results for these variables are reported as year-on-year forecast values from 2012 to 2030; while table D.2 reports the results of these variables as cumulative percentage-changes relative to 2011.
} 
Figure 2: BAU Baseline Forecast Cumulative Percentage Difference in GDP Expenditure Components

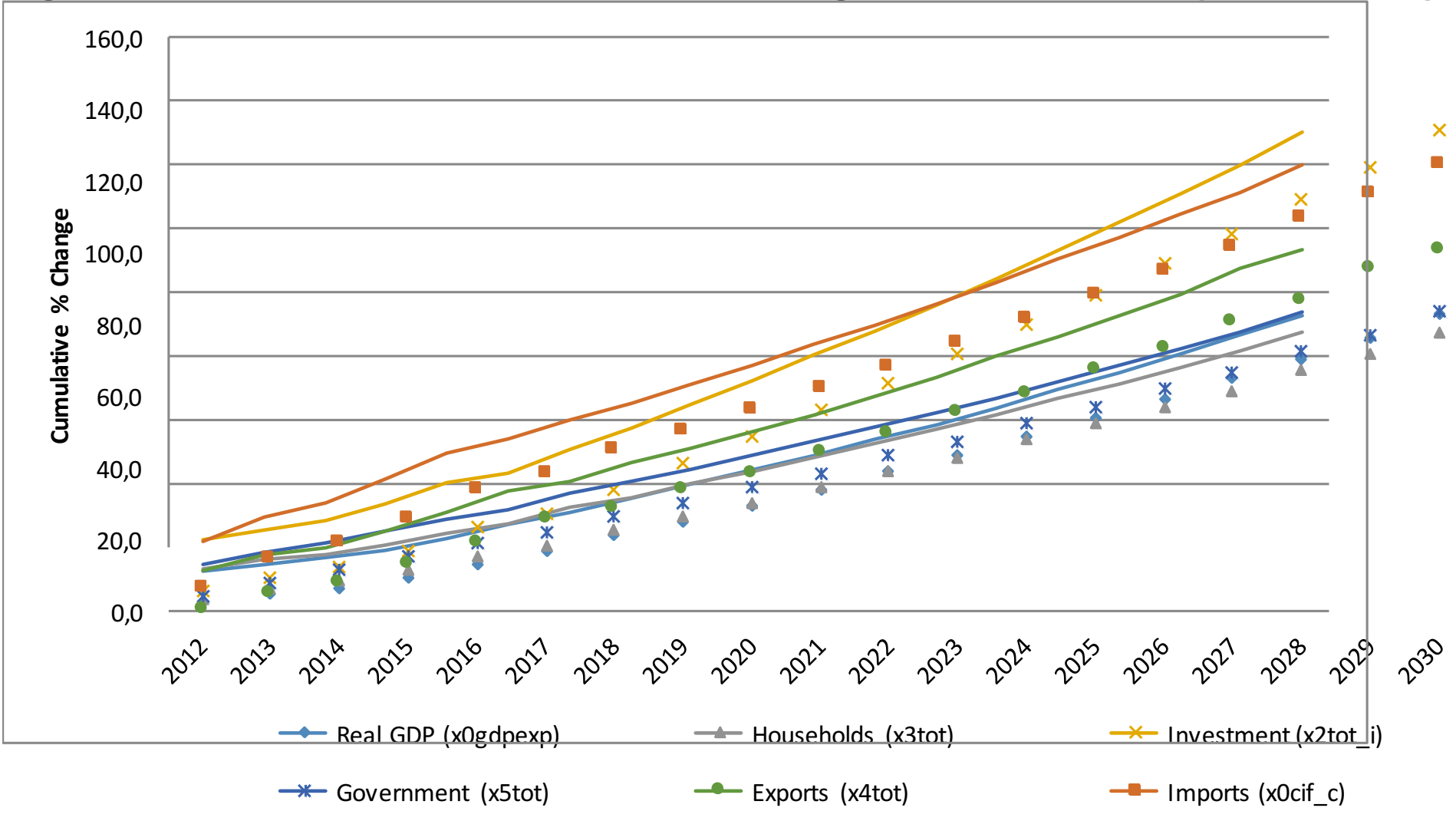

Source: UPGEM (GEMPACK) and Author's Own Calculations 
Figure 3: BAU Baseline Forecast Cumulative Percentage Difference in Electricity Output and Prices

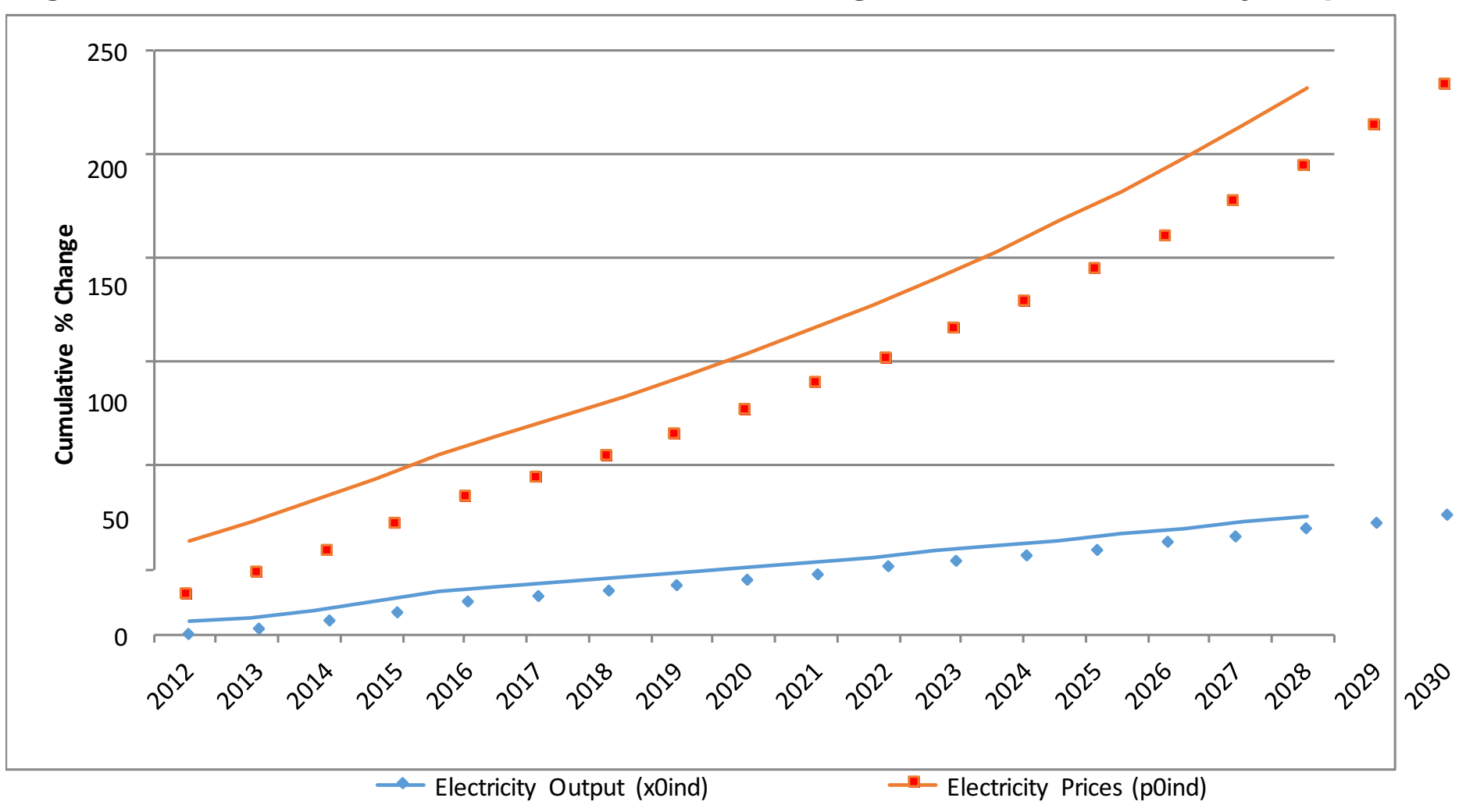

Source: UPGEM (GEMPACK) and Author's Own Calculations 
simulation in which the additional $9600 \mathrm{MW}$ that is scheduled to come online from the sources over the six-year period between 2014 and 2019 is eliminated. Following the methodology explained in section 3 , we will then be able to interpret the absolute percentage change values of the deviations in economic outcomes between the baseline and policy simulations as the contribution facilitated by Medupi and Kusile.

By designing our first policy scenario in this way, we also allow the policy results to be valid for providing insights into another question - how much damage was done to the South African economy between 2008 and 2013 (a similar six year period) due to inadequate supply of electricity, which could be argued, was as a direct consequence of delays in the planning and building of the additional power generation capacity represented by Medupi and Kusile.

Using RunDynam within the GEMPACK suite of programs, the policy shock is introduced in UPGEM as a 'target shock' (tshock) to the change in the electricity industry's output. In this application, the 'target shock' command is used to directly set the growth of electricity supply, overriding any projections made in the baseline, over the period 2014-2019. With new generation capacity between 2014 and 2016 only expected to come from Medupi and Kusile (see Appendix A), electricity supply growth is set to zero per cent in 2014, 2015 and 2016 in the policy run. This simulates the elimination of the new generating capacity expected from Medupi and Kusile over this period. From 2017 other sources of electricity generation, besides Medupi and Kusile, are expected to come online. For the years 2017, 2018 and 2019 electricity supply growth is set to 0.5 per cent. This simulates the elimination of Medupi and Kusile's new generating capacity, whilst retaining the other sources scheduled to come online over this period, including the Ingula pumped storage scheme and other forms of renewable energy (see Appendix A). From 2020 onward, no additional shocks are applied to the economy in the policy run. That is, all 
variables, including electricity supply, are set to grow at the rate projected or determined in the baseline simulation. In the case of electricity supply, this represents an average annual growth rate of around 2 per cent between 2020 and 2030 as projected in the IRP.

In our second policy scenario we simulate a delay of two years in the building of Medupi and Kusile. This allows us to quantify the effect of having less electricity supply available to the economy, relative to the baseline, up to 2021 . This scenario reflects the most recent expectation for the completion of the new build programme by Eskom (Eskom, 2016). A brief discussion of this scenario's policy results are contained in Section 4.4.

\subsection{Policy Simulation Results (First Scenario)}

The policy simulation results produced by UPGEM are reported as cumulative percentage deviations away from the baseline. Interpreting the results of our policy simulation requires special attention in this application. Since we know that Medupi and Kusile will be built and brought online over the period 2014-2019, and our aim is to better understand its role and contribution in the economy, our counterfactual policy scenario eliminates the additional capacity scheduled to come online from these two sources. The absolute value of the deviation from the baseline, in the policy run, may then be interpreted as its contribution.

Three separate tables are used to present the results of the policy run. The first table, Table 1, shows all the main macroeconomic variables including real GDP and its components from both the income and expenditure side. The second table, Table 2 , includes industry level results. The third table, Table 3 , provides a breakdown of the cumulative industry activity deviations relative to the baseline in 2019 (the end of the construction period) and 2030 (the end of our simulation period). This table 
decomposes the total cumulative change in industry activity in these years between local demand (LocalMarket), import substitution (DomShare) and export demand (Export) changes, on a share-weighted basis (Horridge, 2000). These tables are presented at the end of this section.

When using CGE models such as UPGEM, results are interpreted by comparing the values of variables in the baseline to their values in the policy scenario. Deviations are expressed as either percentage changes or ordinary changes (in Rmillions terms) from baseline values. Apart from the exogenous shock itself, only three sources of information are considered when interpreting results from the model. The first is the theoretical specification of the model, the second is the database, and the third is the assumptions imposed via the model's closure along with the shock itself. To avoid tediousness in the reporting of the policy simulation results, the negative impact expected on the economy due to the elimination of Medupi and Kusile's generation capacity in the policy run, will first be presented in an unfiltered manner as produced by UPGEM. At the end of this section, we will interpret our results within the desired context of understanding and measuring the economy-wide contribution Medupi and Kusile are expected to make in the coming years.

\subsubsection{First Round of Impact of the Shock to the Electricity Industry Output}

Figure 4 summarises the impact of the exogenous policy shock on electricity output for the period under consideration. This figure shows the electricity output path in the baseline forecast and policy simulation. With the elimination of Medupi and Kusile's generation capacity in the policy run, areas B and $\mathrm{H}$ may be viewed as 
Figure 4: Electricity Output Deviation in Policy versus Base

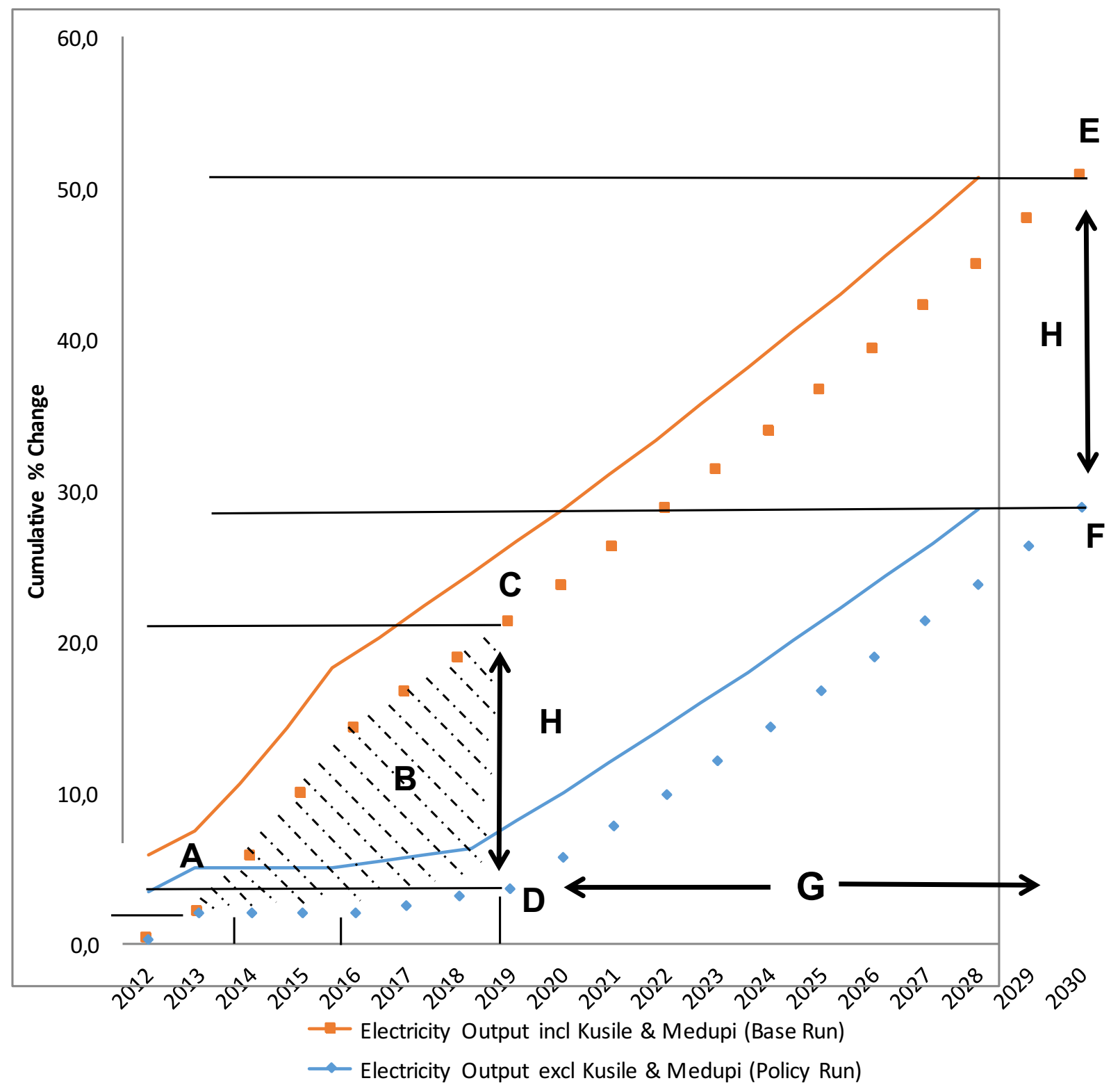

\footnotetext{
*** Electricity capacity in $2011=44000 \mathrm{MW}$

A: Electricity output grows at the same rate in both the baseline and the policy simulations up to 2013

B: The shaded area represents the 'absence of Kusile and Medupi' for the period 2014-2019 where the policy shock was imposed

Electricity output growth is limited to $0.0 \%$ per annum for the years 2014, 2015 and 2016

Electricity output growth is limited to $0.5 \%$ per annum for the years 2017, 2018 and 2019

(Electricity output growth beyond 2020, grows at $2 \%$ per annum, same as the baseline)

C: Electricity output growth in the baseline was forecasted to be $21.1 \%$ in 2019 , which represents total electricity capacity of $53297 \mathrm{MW}$

D: Electricity output growth in the policy simulation is forecasted to be $3.5 \%$ in 2019 which represents total electricity capacity of $45533 \mathrm{MW}$

E: Electricity output growth in the baseline was forecasted to be $50.61 \%$ in 2030 , which represents total electricity capacity of $66268 \mathrm{MW}$

F: Electricity output growth in the policy simulation is forecasted to be $28.7 \%$ in 2030 , which represents total electricity capacity of $56615 \mathrm{MW}$

G: Electricity output from 2020 and beyond grows at $2.0 \%$ per annum in both the baseline and the policy simulation

H: The cumulative percentage difference in electricity output between the baseline and the policy simulation is $14.5 \%$ calculated for 2030 as

$\left[(\right.$ difference $\left.) /(\text { base })^{*} 100\right]=\left[\left(44000^{*} 1.2867-44000^{*} 1.5061\right) /\left(44000^{*} 1.5061\right)^{*} 100\right]=\left[(56615-66268) /(66268)^{*} 100\right]=\left[(-9654) /(66268)^{*} 100\right]=14.5 \%$
} 
the share in projected electricity supply in the baseline expected to come from these two power stations.

In the baseline, electricity output grows from $44000 \mathrm{MW}$ in 2011 to $53297 \mathrm{MW}$ in 2019 and to $66268 \mathrm{MW}$ in 2030 . This represents an increase in electricity output of 21.1 per cent between 2011 and 2019; and 50.7 per cent between 2011 and 2030 . This growth path follows the projections laid out in the latest IRP document (DoE, 2013). In the policy simulation, electricity output grows from $44000 \mathrm{MW}$ in 2011 to $45533 \mathrm{MW}$ in 2019 and to $56615 \mathrm{MW}$ in 2030 and simulates the evolution of the economy minus the generation capacity expected to come from Medupi and Kusile. All other sources of electricity generation, outside of Medupi and Kusile, continue to come online in the policy run as scheduled in the baseline. In the policy simulation, electricity output only grows 3.5 per cent between 2011 and 2019 with the elimination of Medupi and Kusile's generation capacity and by 28.7 per cent between 2011 and 2030. The small increase in electricity output capacity between 2017 and 2019 will come from Ingula and other renewable sources scheduled to come online. As shown in Figure 5, UPGEM projects that restricting electricity output between 2014 and 2019 will reduce cumulative electricity output growth in 2030 by 14.5 per cent relative to the baseline.

The next impact to be examined after the exogenous change to electricity output capacity in the policy run should be electricity prices. In the baseline, electricity prices are exogenously set according to Eskom's projected multi-year price determination (MYPD3) framework. In the policy run we allow electricity prices to 
Figure 5: Real GDP Deviation in Policy versus Base

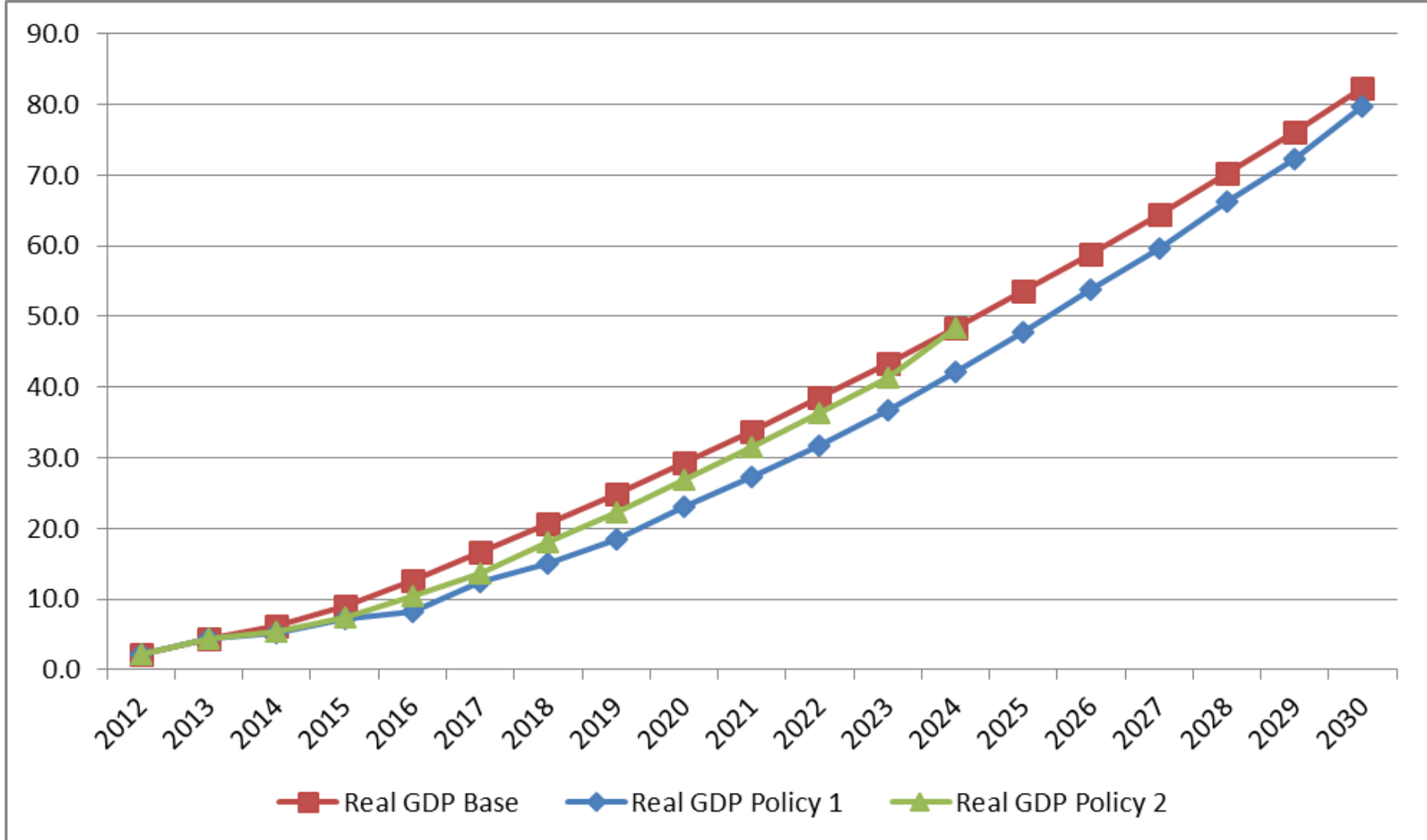

Source: UPGEM (GEMPACK) and Author's Own Calculations 
respond endogenously to the exogenous shock to electricity supply. Despite the regulated pricing structure of electricity in South Africa assumed in the baseline, this closure setting is required in order to achieve sensible policy simulation results within a general equilibrium model. In the unlikely event that regulators do not allow electricity prices to change relative to the baseline after such a large exogenous shock to electricity output, we may simply adjust our interpretation of any changes to electricity prices predicted in the policy simulation as a change in the excess demand for electricity.

Electricity prices start rising immediately, relative to the baseline, after the imposition of our policy shock that reduces electricity output. By 2030, electricity prices are cumulatively 118.4 per cent higher relative to the baseline. That is, by eliminating Medupi and Kusile's additional power generation, electricity prices would need to more than double relative to the baseline, if allowed to move freely, in order to clear the market. This result is not surprising given our policy simulation design the scarcer a commodity becomes the higher its value is likely to become. Within the context of this paper and the regulatory environment in South Africa, we may interpret this result, as showing that Medupi and Kusile's capacity will significantly reduce the excess demand for electricity, and subsequent blackouts, in the economy over the simulation period. The impact on macroeconomic and industry variables, explained next in sub-sections 4.3.2 and 4.3.3 respectively, follows directly from the exogenous shock imposed on electricity output described in this section.

\subsubsection{Macroeconomic Results}

As shown in Table 1, the macroeconomic impacts following the shock to the electricity industry are generally negative, as may be expected given our simulation design. Real GDP falls by 0.44 per cent in 2014 alone and with 3.15 per cent by 
Table 1: Selected Macro Results (Cumulative Percentage Difference Relative to Baseline)

\begin{tabular}{|c|c|c|c|c|c|c|c|c|}
\hline Macro Variables & 2014 & 2015 & 2016 & 2017 & 2018 & 2019 & 2020 & 2030 \\
\hline Real GDP (x0gdpexp) & $-0,44$ & $-0,90$ & $-1,61$ & $-2,37$ & $-2,70$ & $-3,15$ & $-3,11$ & $-1,00$ \\
\hline Real GNE (xOgne) & $-1,33$ & $-2,24$ & $-3,40$ & $-4,35$ & $-4,01$ & $-4,16$ & $-3,11$ & $-0,27$ \\
\hline Households (x3tot) & $-0,98$ & $-1,48$ & $-2,26$ & $-2,89$ & $-2,55$ & $-2,76$ & $-2,10$ & $-0,57$ \\
\hline Investment (x2tot_i) & $-2,77$ & $-5,26$ & $-7,85$ & $-9,94$ & $-9,58$ & $-9,49$ & $-7,02$ & 1,22 \\
\hline Government (x5tot) & $-0,98$ & $-1,48$ & $-2,26$ & $-2,89$ & $-2,55$ & $-2,76$ & $-2,10$ & $-0,57$ \\
\hline Exports (x4tot) & 1,30 & 1,65 & 1,87 & 1,56 & 0,12 & $-0,74$ & $-2,35$ & $-1,49$ \\
\hline Imports (x0cif_c) & $-1,69$ & $-2,68$ & $-3,82$ & $-4,61$ & $-3,98$ & $-3,91$ & $-2,53$ & 0,46 \\
\hline Capital (x1cap_i) & $-0,01$ & $-0,20$ & $-0,56$ & $-1,12$ & $-1,84$ & $-2,48$ & $-3,07$ & $-2,16$ \\
\hline Labour (emp_jobs) & $-0,81$ & $-1,42$ & $-2,25$ & $-2,98$ & $-2,90$ & $-3,10$ & $-2,51$ & 0,49 \\
\hline Technical Change (a_cont) & $-0,01$ & $-0,04$ & $-0,10$ & $-0,18$ & $-0,17$ & $-0,16$ & $-0,15$ & 0,03 \\
\hline Tax Carrying Flows (tcf_cont) & $-0,05$ & $-0,10$ & $-0,17$ & $-0,24$ & $-0,24$ & $-0,26$ & $-0,14$ & 0,99 \\
\hline Real Wage (real_wage_c) & $-0,41$ & $-1,12$ & $-2,24$ & $-3,73$ & $-5,18$ & $-6,73$ & $-7,97$ & $-11,84$ \\
\hline Imp/Dom Twist (twist_c) & 0,00 & 0,00 & 0,00 & 0,00 & 0,00 & 0,00 & 0,00 & 0,00 \\
\hline Cap/Lab Twist (twist_i) & 0,00 & 0,00 & 0,00 & 0,00 & 0,00 & 0,00 & 0,00 & 0,00 \\
\hline GDP Deflator (p0gdpexp) & $-1,64$ & $-1,72$ & $-1,96$ & $-1,75$ & $-0,23$ & 0,16 & 1,58 & $-0,07$ \\
\hline GNE Deflator (p0gne) & $-1,46$ & $-1,51$ & $-1,72$ & $-1,54$ & $-0,22$ & 0,06 & 1,25 & $-0,27$ \\
\hline Real Devaluation (p0realdev) & 1,68 & 1,76 & 2,01 & 1,78 & 0,23 & $-0,16$ & $-1,56$ & 0,06 \\
\hline Terms of Trade (p0toft) & $-0,45$ & $-0,60$ & $-0,70$ & $-0,63$ & $-0,15$ & 0,15 & 0,73 & 0,47 \\
\hline Export Price Index (p4tot) & $-0,45$ & $-0,60$ & $-0,70$ & $-0,63$ & $-0,15$ & 0,15 & 0,73 & 0,46 \\
\hline Import Price Index (p0imp_c) & 0,00 & 0,00 & 0,00 & 0,00 & 0,00 & 0,00 & 0,00 & 0,00 \\
\hline Nominal Exchange Rate (phi) & 0,00 & 0,00 & 0,00 & 0,00 & 0,00 & 0,00 & 0,00 & 0,00 \\
\hline Consumer Price Index (p3tot) & $-0,94$ & $-0,80$ & $-0,68$ & $-0,23$ & 0,96 & 1,45 & 2,47 & 1,76 \\
\hline Labour Prices (p1lab_io) & $-1,34$ & $-1,91$ & $-2,89$ & $-3,94$ & $-4,25$ & $-5,35$ & $-5,68$ & $-10,25$ \\
\hline Capital Rentals (p1cap_i) & $-5,19$ & $-7,66$ & $-10,49$ & $-12,05$ & $-8,84$ & $-7,79$ & $-2,56$ & 3,03 \\
\hline Investment Prices (p2tot_i) & $-2,57$ & $-2,83$ & $-3,43$ & $-3,30$ & $-0,98$ & $-0,61$ & 1,58 & $-0,44$ \\
\hline
\end{tabular}

Source: UPGEM (GEMPACK) and Author's Own Calculations 
2019, in cumulative terms, relative to the baseline. The loss in real GDP by 2019 represents around R113 billion at 2011 prices. Post-shock, the economy recovers slightly to 1.0 per cent below the baseline by 2030 . Figure 5 illustrates this deviation in real GDP between the baseline and policy simulations. The policy run's gradual return to the baseline over time is to be expected as the relative contribution of Medupi and Kusile is diluted by the building of other sources of electricity generation over the simulation period. By interpreting the absolute values of our results within the context of this study, it clearly shows the positive impact that adding Medupi and Kusile's generation capacity, as expected in the baseline, will have on the performance of the economy.

In our policy run, the depressing effect caused by the fall in GDP initially reduces inflation. However, the long-term impact of the supply-side constraints imposed in the policy run ultimately increases inflation with 2.47 per cent by 2020 and 1.75 per cent by 2030 , relative to the baseline. The higher level of inflation is mainly caused by the general equilibrium impact of the significantly higher price of electricity. With less electricity available at higher prices, it is no surprise that this supply shock will cause inflation to rise. We can therefore view the role of Medupi and Kusile as improving the productive capacity in the country over the medium to long term, thereby reducing cost-push inflation in the long run. 
As expected, with real GDP falling, all components from both the income and the expenditure side also contract relative to the baseline. The exception is exports, which for the period 2014-2018, increases relative to the baseline. Export prices decline for the years 2014-2018, in line with the lower rate of inflation. With import prices exogenous in the policy run, the lower value of domestically produced goods explains the lower terms of trade and real devaluation in the short to medium term. With downward sloping export demand curves, this result explains the increase in aggregate exports and also why most export oriented and tourism related industries are relative winners in the short term.

This sequence of events allows us to understand the increase in total export demand of 1.30 per cent in 2014, by 1.65 per cent in 2015, by 1.87 per cent in 2016 and by 1.56 in 2017 relative to the baseline. From 2019 and beyond, export prices start rising on the back of higher inflation and production costs, leading to total export demand declining by 1.49 per cent relative to the baseline by 2030 . Imports fall in line with a reduction in local consumption. Imports decline by 1.69 per cent in 2014 , by 2.68 per cent in 2015, by 3.82 per cent in 2016 and by 4.61 percent in 2017 relative to the baseline. Post-shock, imports do recover somewhat in line with consumption, but as explained later, this result does not represent all good news as it comes at the cost of lower savings and investment expenditure.

Over the medium term during which the policy shock is imposed, capital stocks are expected to fall in line with GDP, which is 3.15 per cent lower in 2019 . With that much less capital required investment expenditure must fall dramatically. Our results confirm this and show that investment expenditure will decline by 7.85 per cent in 2016 and 9.94 per cent in 2019, relative to the baseline. Household consumption falls by 2.26 per cent in 2016, by 2.76 in 2019 and by 0.57 per cent in 2030 relative to the baseline. At the same time, household's average propensity to consume from 
its disposable income rises slightly relative to the baseline. This result can be interpreted as an attempt from households to buffer itself against the negative impact of the shock. The direct implication of rising average propensity to consume when disposable income is falling is a decline in household savings. By assumption, government expenditure falls in line with household consumption. With tax revenues falling by an even larger percentage on the back of reduced economic activity, the budget deficit widens relative to the baseline. When evaluating the results and recovery seen by 2030 , it is clear the part of this recovery involves substituting of capital creation for higher consumption. That is, consumers are buying more consumer goods and allocating fewer resources to the building of capital goods. This is likely to affect the economy's growth potential in the very long run.

The results regarding labour are also interesting. As may be expected with significantly lower production and capital creation occurring in the short to medium term, employment also initially falls in line with these variables. However, the biggest impact on the labour market in the long run is due to reduced levels of productivity, stemming from the lack of electricity generation capacity and investment expenditure. This causes real wages, often seen as an indicator of labour productivity in the long run, to fall dramatically over the simulation period. By 2020 real wages are down 7.97 per cent and by 11.84 in 2030 , relative to the baseline. The slightly higher employment levels seen in 2030 should therefore be interpreted alongside the outcome of significantly lower real wages. Should Medupi and Kusile be brought online as expected in the baseline, its contribution on a macroeconomic level is therefore shown as being unambiguously good for the economy. 
Table 2: Industry Output Results (Cumulative Percentage Difference Relative to Baseline)

\begin{tabular}{|c|c|c|c|c|c|c|c|c|}
\hline Industry & 2014 & 2015 & 2016 & 2017 & 2018 & 2019 & 2020 & 2030 \\
\hline Agriculture & $-0,06$ & $-0,12$ & $-0,29$ & $-0,54$ & $-0,76$ & $-1,01$ & $-1,13$ & 0,18 \\
\hline Coal Lignite & 0,02 & 0,05 & $-0,05$ & $-0,27$ & $-0,64$ & $-1,15$ & $-1,65$ & $-1,98$ \\
\hline Mining of Metal Ores & 0,10 & 0,19 & 0,14 & $-0,05$ & $-0,42$ & $-0,91$ & $-1,38$ & $-0,87$ \\
\hline Other Mining & 0,12 & 0,22 & 0,18 & $-0,03$ & $-0,44$ & $-0,99$ & $-1,55$ & $-1,53$ \\
\hline Food & $-0,25$ & $-0,46$ & $-0,85$ & $-1,30$ & $-1,44$ & $-1,71$ & $-1,65$ & 0,25 \\
\hline Beverages, Tobacco & $-0,06$ & 0,01 & 0,02 & 0,02 & 0,04 & $-0,06$ & $-0,10$ & 1,41 \\
\hline Textiles, Footwear & $-0,35$ & $-0,90$ & $-1,82$ & $-2,87$ & $-3,25$ & $-3,74$ & $-3,62$ & $-0,93$ \\
\hline Petroleum, Chemicals & $-0,17$ & $-0,87$ & $-2,11$ & $-3,73$ & $-4,98$ & $-6,14$ & $-6,83$ & $-5,00$ \\
\hline Iron \& Steel & $-0,16$ & $-1,73$ & $-3,88$ & $-6,38$ & $-8,13$ & $-9,36$ & $-9,78$ & $-5,14$ \\
\hline Other Metal Equipment & 0,20 & $-0,30$ & $-1,12$ & $-2,25$ & $-3,41$ & $-4,31$ & $-4,93$ & $-1,10$ \\
\hline Electrical Machinery & $-0,91$ & $-2,18$ & $-3,62$ & $-4,99$ & $-5,53$ & $-5,89$ & $-5,30$ & 0,70 \\
\hline Transport Equipment & $-0,07$ & $-0,41$ & $-0,93$ & $-1,55$ & $-2,05$ & $-2,40$ & $-2,47$ & 1,69 \\
\hline Other Manufacturing & 0,00 & $-0,26$ & $-0,72$ & $-1,36$ & $-2,00$ & $-2,54$ & $-2,88$ & 0,16 \\
\hline Electricity & $-2,91$ & $-6,20$ & $-9,37$ & $-11,99$ & $-13,29$ & $-14,56$ & $-14,56$ & $-14,56$ \\
\hline Water & $-0,13$ & $-0,34$ & $-0,67$ & $-1,10$ & $-1,43$ & $-1,74$ & $-1,88$ & $-0,38$ \\
\hline Construction & $-2,45$ & $-4,85$ & $-7,34$ & $-9,43$ & $-9,33$ & $-9,33$ & $-7,20$ & 0,85 \\
\hline Trade & $-0,26$ & $-0,75$ & $-1,57$ & $-2,54$ & $-3,21$ & $-3,88$ & $-4,09$ & $-1,09$ \\
\hline Hotel \& Restaurants & 0,20 & 0,42 & 0,54 & 0,53 & 0,26 & $-0,18$ & $-0,72$ & $-1,11$ \\
\hline Transport Services & 0,05 & 0,10 & 0,01 & $-0,19$ & $-0,53$ & $-0,98$ & $-1,41$ & $-0,50$ \\
\hline Post \& Communication Services & $-0,02$ & $-0,04$ & $-0,18$ & $-0,42$ & $-0,72$ & $-1,10$ & $-1,40$ & 0,21 \\
\hline Business & $-0,21$ & $-0,47$ & $-0,91$ & $-1,40$ & $-1,71$ & $-2,04$ & $-2,09$ & 0,38 \\
\hline General Government & $-0,95$ & $-1,44$ & $-2,21$ & $-2,82$ & $-2,47$ & $-2,65$ & $-1,98$ & $-0,29$ \\
\hline Education & $-0,39$ & $-0,75$ & $-1,29$ & $-1,84$ & $-1,93$ & $-2,15$ & $-1,91$ & 0,52 \\
\hline Health \& Social Services & $-0,32$ & $-0,63$ & $-1,09$ & $-1,57$ & $-1,69$ & $-1,90$ & $-1,74$ & 0,53 \\
\hline Other Services & $-0,16$ & $-0,28$ & $-0,47$ & $-0,67$ & $-0,73$ & $-0,85$ & $-0,80$ & 1,09 \\
\hline
\end{tabular}

Source: UPGEM (GEMPACK) and Author's Own Calculations 


\subsubsection{Industry Results}

As shown in Table 2, on an industry level, the electricity and construction industries are the biggest contributors to the negative changes in overall industry output. This is expected given that these are the two industries most directly affected by the shock imposed in the policy simulation. The electricity industry is directly affected by the restriction in electricity output growth imposed during the 2014-2019 period. The construction industry is affected by the significant slowdown in investment activities that arises as a consequence of the shock. This can also be associated with the adjustment of the economy to a lower capital stock, which consequently causes a negative deviation in the ratio of investment relative to GDP. The iron and steel industry, a heavy user of electricity as an intermediate input, is also negatively affected by the policy, with industry prices significantly higher over time relative to the baseline, leading to production and export demand in the industry declining strongly relative to the baseline.

Export-oriented industries such as mining and tourism related services seem to be taking advantage of the real devaluation of the currency immediately after the shock, and do relatively well for the period 2014-2016, given the overall performance of the economy. As confirmed in Table 3, the electricity and construction industries are the biggest losers when looking at the domestic market effect in isolation. The electricity industry is down as a consequence of the imposed shock. Since the electricity industry uses a lot of coal as inputs, the coal mining industry loses in the domestic market, which slightly depresses coal prices. However, it is able to partially offset this loss in the domestic market with increased exports, making coal a relative winner in overall net terms. 
Table 3: Breakdown of Total Industry Activity (Deviations from Baseline in 2019 and 2030)

\begin{tabular}{|c|c|c|c|c|c|c|c|c|}
\hline & \multicolumn{4}{|c|}{2019} & \multicolumn{4}{|c|}{2030} \\
\hline Industry Activity & 1 LocalMarket & 2 DomShare & 3 Export & 4 Total & 1 LocalMarket & 2 DomShare & 3 Export & 4 Total \\
\hline Agriculture & $-1,23$ & $-0,35$ & 0,51 & $-1,07$ & 0,07 & 0,02 & 0,09 & 0,18 \\
\hline Coal Lignite & $-1,42$ & $-3,49$ & 3,70 & $-1,20$ & $-2,72$ & $-2,53$ & 3,18 & $-2,07$ \\
\hline Mining of Metal Ores & $-0,59$ & $-1,48$ & 1,13 & $-0,94$ & $-0,83$ & $-0,61$ & 0,54 & $-0,91$ \\
\hline Other Mining & $-1,85$ & 0,22 & 0,63 & $-1,01$ & $-1,66$ & $-0,04$ & 0,15 & $-1,55$ \\
\hline Food & $-1,88$ & $-0,13$ & 0,21 & $-1,79$ & 0,15 & 0,01 & 0,09 & 0,25 \\
\hline Beverages, Tobacco & $-0,54$ & $-0,69$ & 1,11 & $-0,13$ & 0,74 & $-0,25$ & 0,91 & 1,41 \\
\hline Textiles, Footwear & $-2,61$ & $-0,42$ & $-0,23$ & $-3,27$ & 0,03 & $-0,20$ & $-0,18$ & $-0,35$ \\
\hline Petroleum, Chemicals & $-2,87$ & $-0,65$ & $-2,84$ & $-6,36$ & $-0,89$ & $-0,50$ & $-3,69$ & $-5,08$ \\
\hline Iron \& Steel & $-4,18$ & 0,36 & $-5,93$ & $-9,75$ & $-0,96$ & 0,79 & $-4,93$ & $-5,10$ \\
\hline Other Metal Equipment & $-1,90$ & 0,03 & $-2,96$ & $-4,83$ & $-0,22$ & 0,11 & $-1,23$ & $-1,34$ \\
\hline Electrical Machinery & $-5,95$ & $-0,34$ & 0,39 & $-5,90$ & $-0,33$ & 0,19 & 0,63 & 0,49 \\
\hline Transport Equipment & $-3,08$ & $-0,04$ & 0,58 & $-2,54$ & $-0,09$ & 0,39 & 1,16 & 1,46 \\
\hline Other Manufacturing & $-3,18$ & $-0,07$ & 0,41 & $-2,84$ & $-0,14$ & 0,01 & 0,20 & 0,07 \\
\hline Electricity & $-11,10$ & $-3,85$ & $-1,04$ & $-15,99$ & $-11,61$ & $-3,10$ & $-1,29$ & $-15,99$ \\
\hline Water & $-1,82$ & 0,02 & 0,00 & $-1,80$ & $-0,36$ & $-0,02$ & 0,00 & $-0,38$ \\
\hline Construction & $-8,90$ & $-0,01$ & 0,01 & $-8,90$ & 0,95 & 0,00 & 0,01 & 0,96 \\
\hline Trade & $-3,68$ & $-0,10$ & 0,12 & $-3,66$ & $-0,86$ & $-0,04$ & 0,09 & $-0,81$ \\
\hline Hotel \& Restaurants & $-0,78$ & $-0,48$ & 0,98 & $-0,27$ & $-0,42$ & 0,09 & $-0,60$ & $-0,93$ \\
\hline Transport Services & $-1,51$ & $-0,56$ & 1,05 & $-1,02$ & $-0,69$ & $-0,12$ & 0,41 & $-0,40$ \\
\hline Post \& Communication Services & $-1,51$ & $-0,71$ & 1,07 & $-1,15$ & $-0,17$ & $-0,13$ & 0,52 & 0,22 \\
\hline Business & $-2,52$ & $-0,22$ & 0,28 & $-2,46$ & 0,03 & $-0,05$ & 0,18 & 0,16 \\
\hline General Government & $-2,73$ & 0,01 & 0,00 & $-2,72$ & $-0,25$ & 0,01 & 0,00 & $-0,24$ \\
\hline Education & $-2,22$ & 0,01 & 0,00 & $-2,21$ & 0,57 & 0,00 & 0,00 & 0,57 \\
\hline Health \& Social Services & $-1,99$ & $-0,01$ & 0,04 & $-1,96$ & 0,53 & 0,00 & 0,04 & 0,57 \\
\hline Other Services & $-1,89$ & 0,00 & 0,37 & $-1,51$ & 0,16 & 0,06 & 0,29 & 0,52 \\
\hline
\end{tabular}

Source: UPGEM (GEMPACK) and Author's Own Calculations 


\subsection{Policy Simulation Results (Second Scenario)}

Our second policy scenario adds further empirical evidence of the effects of a lack of adequate electricity supply on the local economy's growth prospects. By simulating a two-year delay in the build programme of Medupi and Kusile, we are able to quantify the impact of such a delay, which serves to inform policymakers and key stakeholders in making their projections. Latest reports from Eskom indicate that a two-year delay, relative to the original build schedule, is likely given the labour disruptions that have occurred on site and technical difficulties that have been encountered.

Simulation results for our second scenario indicate that GDP will be as high as 1 per cent below base in 2017 and only return to baseline levels in 2022, one year after Medupi and Kusile have been fully brought online. Figure 5 shows this deviation in GDP growth, relative to the baseline, for the second policy scenario. These simulation results provide further evidence regarding the urgency of restoring adequate electricity supply in order to facilitate the levels of growth the country envision in its baseline projections.

\subsection{General Remarks}

As noted throughout this section, the generally negative results found in the first policy simulation could be inverted if we wish to use our analysis to measure the expected contribution of Medupi and Kusile in the South African economy. In this way, our results clearly show the additional generation capacity scheduled to come from these new power plants will improve the economy's ability to grow and attract investment. 


\section{Conclusion and Policy Implications}

This paper analysed the economy-wide contribution that the additional electricity generation capacity from Medupi and Kusile will bring to the South African economy in the medium to long run. We used a dynamic CGE model to conduct our analysis. In order to isolate and measure the contribution of Medupi and Kusile, we ran a counterfactual policy simulation in which the additional generation capacity of 9600 MW that is scheduled to come from these new power stations between 2014 and 2019 is eliminated, relative to a business-as-usual baseline simulation in which they are brought online as expected. We then interpreted the absolute values of the deviations in economic outcomes between the baseline and policy simulations as the contribution of Medupi and Kusile. The simulations were run within the context of the Department of Energy's Integrated Resource Plan and projected economic growth figures for South Africa up to 2030. All additional electricity capacity expansion, outside of Medupi and Kusile, was simulated to continue as planned. Therefore, in the first policy run, electricity supply available to the economy remained $9600 \mathrm{MW}$ short of that projected in the baseline after 2020. The generation capacity of Medupi and Kusile represents a relatively large share of projected electricity supply in 2020 . Although this share will gradually decline up to 2030 as other sources of electricity 
come online, its contribution in terms of facilitating economic growth and investment is shown to remain crucial throughout the simulation period. The environmental impacts of these two new coal-fired power stations were not explicitly accounted for in our CGE analysis.

The first conclusion that emerged from our analysis was that economic growth will be severely harmed in the medium term without the additional electricity generation capacity scheduled to be brought online through Medupi and Kusile. This result also supports the view that inadequate electricity capacity in recent years has already cost the South African economy billions of Rands. The results from our second policy simulation scenario also highlight the short-term losses the economy will suffer should there be further delays in the completion of the new power stations. On a macro level, we found that investment expenditure, in particular, is heavily dependent on the expected growth in electricity capacity and infrastructure. Up to 2019 , around 10 per cent of investment activity is facilitated, directly or indirectly, by the building of Medupi and Kusile. Given its close link to real investment expenditure on a macro level, the construction industry gains the most from the additional activity allowed for by the building of these two power stations over this period.

The second conclusion that emerged from the modelling simulations was that the problem of excess demand relative to tight supply in the electricity market will be greatly relieved once the additional capacity from Medupi and Kusile is installed. The current conditions, which have contributed to widespread blackouts and load shedding (the local term for electricity rationing) in the country since 2008 , must be considered within the context of electricity's regulated pricing structure. Eskom is not allowed to automatically raise electricity prices when demand exceeds supply, as might be the case in other free market enterprises. The model shows us that if electricity prices were subject to market forces, the building of Medupi and Kusile's 
additional capacity would have contributed to a significant slowdown in electricity price increases over the next decade. Within the context of Eskom as a state-owned enterprise subject to regulated pricing, we interpret this particular result as showing that the building of Medupi and Kusile will lead to fewer blackouts as adequate reserve margins in the electricity sector are restored.

Overall, the research presented in this study shows that the local economy will benefit significantly through the new power generation scheduled to come from Medupi and Kusile. The building of these new coal-fired power stations was challenged on two fronts in the literature. The first relates to environmental concerns and the second to a possible over supply of electricity, within the context of slowing demand in the face of rising electricity prices, and opportunity cost implications. On the first issue, it is widely recognised that coal is likely to remain South Africa's most abundant and cheapest option for electricity generation for some time (Eskom, 2014a). By building new power stations based on clean coal technologies, such as Medupi and Kusile, sufficient and relatively cost-effective base load can be provided to the South African economy whilst reducing its environmental footprint relative to supply from existing coal-fired power stations (Eskom, 2014b). Once additional base load in the form of nuclear power is built, supplemented by various renewable sources of electricity as outlined in the IRP, South Africa's fleet of old coal-fired plants can then be decommissioned. As a result, the country's overall electricity generation mix in 2030 is projected to be less dependent on coal-fired technologies and friendlier to the environment. However, a coal-free energy mix is, unfortunately, not an economically viable option in the near term, making the building of modern coal-fired stations such as Medupi and Kusile a necessary evil - one that attempts to strike a reasonable balance between the need to protect the environment and the economic realities of the day. 
On the second issue, our simulation results clearly show the need for both stations' additional capacity in order to facilitate economic growth, prevent widespread blackouts and reduce upward pressure on electricity prices. Our results also suggest that growth in electricity demand will be large enough to warrant the building of Medupi and Kusile, despite recent and projected increases in electricity prices. One exception applies to this projection. In the event that significant technological progress in combination with appropriate economic policy changes, as suggested in Inglesi-Lotz \& Blignaut (2014), allows users to require or demand much less electricity to fulfil their energy needs, leading to an improvement in energy efficiency, the second of the two new coal-fired power stations may well prove to deliver excess capacity to the economy in the near term. However, if we are to replace the existing fleet of old coal-fired plants, the capacity of both new stations will be required in order to provide adequate base load.

This paper only considered the economic impact of additional electricity capacity scheduled to come online in South Africa through Medupi and Kusile. Further research, already in-progress as described in Bohlmann, J.A. et al. (2015), is required to get a more holistic view of the impact and requirements regarding South Africa's future electricity generation capacity and mix. In addition, recent work on the estimation of electricity price elasticities during a period of interrupted and constrained supply; different financing options for future build programs and their implications; environmental considerations; implementation of a carbon-tax; new technologies becoming viable and cost implications of moving to renewable sources of electricity must all be carefully considered within a detailed general equilibrium framework. The importance and need for continued research in this field should not be underestimated. 


\section{Acknowledgements}

The authors would like to acknowledge the financial support received from Economic Research Southern Africa (ERSA) and the insightful comments received from two anonymous referees that improved the paper.

\section{References}

Adams, P.D., Parmenter, B.R., 2013. Computable general equilibrium modeling of environmental issues in Australia: economic impacts of an emission trading scheme, in: Dixon, P.B., Jorgenson, D.W. (Eds.), Handbook of Computable General Equilibrium Modeling, North-Holland, Amsterdam, pp. 553-657.

Alton, T., Arndt, C., Davies, R., Hartley, F., Makrelov, K., Thurlow, J., Ubogu, D., 2013. Introducing carbon taxes in South Africa. Applied Energy. 116, 344-354.

Armington, P.S., 1969. A theory of demand for products distinguished by place of production. International Monetary Fund Staff Papers. XVI, 159-178.

Blignaut, J.N., 2012. Climate Change: The Opportunity Cost of Medupi and Kusile Power Stations. Journal of Energy in Southern Africa. 23(4), 67-75.

Blignaut, J., Inglesi-Lotz, R., Weideman, J., 2015. Sectoral electricity elasticities in South Africa: before and after the supply crisis. South African Journal of Science. 111(9/10), 1-7.

Bohlmann, H.R., Dixon, P.B., Rimmer, M.T., Van Heerden, J.H., 2015. The impact of the 2014 platinum mining strike in South Africa: an economy-wide analysis. Economic Modelling. 51(2015), 403-411.

Bohlmann, J.A., Bohlmann, H.R., Inglesi-Lotz, R., Van Heerden, J.H., 2015. How would changes in the electricity generation-mix affect the South African economy and environment in the long run, in: proceedings of the 2015 Economics Society of South Africa Conference. Cape Town, South Africa.

CEPII, 2012. The great shift: macroeconomic projections for the world economy at the 2050 horizon. CEPII working paper 2012-03. Centre D'Etudes Prospectives Et D'Informations Internationales, Paris.

Department of Energy, 2011. Integrated Resource Plan for Electricity 2010-2030, Revision 2, March 2011. Department of Energy, Pretoria.

Department of Energy, 2013. Integrated Resource Plan for Electricity 2010-2030: Updated Report, November 2013. Department of Energy, Pretoria. 
Dixon, P.B., Koopman, R.B., Rimmer, M.T., 2013. The MONASH style of computable general equilibrium modeling: a framework for practical policy analysis, in Dixon, P.B., Jorgenson, D.W. (Eds.), Handbook of Computable General Equilibrium Modeling.. North-Holland, Amsterdam, pp. 23-103.

Dixon, P.B., Rimmer, M.T., 2002. Dynamic general equilibrium modeling for forecasting and policy: a practical guide and documentation of $\mathrm{MONASH}$, North-Holland, Amsterdam.

Dixon, P.B., Rimmer, M.T., 2005. Reducing the barriers to entry in dynamic CGE modelling, in: proceedings of the 8th Annual Conference on Global Economic Analysis. Lübeck, Germany.

EIUG, 2015. Who is the EIUG - Infographic. Energy Intensive Users Group of South Africa, Johannesburg. Available online at: http://www.eiug.org.za. Accessed on 20 April 2016.

Eskom, 2007. Build programme in South Africa. Fact Sheet NB0001. Eskom Holdings SOC Limited, Pretoria.

Eskom, 2010. Kusile and Medupi coal-fired power stations under construction. Fact Sheet COP17. Eskom Holdings SOC Limited, Pretoria.

Eskom, 2014a. Coal in South Africa. Fact Sheet CO0007 (Rev 12). Generation Communication, Eskom Holdings SOC Limited, Pretoria, January 2014.

Eskom, 2014b. Building a coal fired power station. Fact Sheet CO0003 (Rev 7). Generation Communication, Eskom Holdings SOC Limited, Pretoria, February 2014

Eskom, 2014c. Generation plant mix. Fact Sheet GXO001 (Rev 14). Generation Communication, Eskom Holdings SOC Limited, Pretoria, May 2014

Eskom, 2014d. New build programme online documentation. Eskom Holdings SOC Limited, Pretoria, Available online at: http://www.eskom.co.za. Accessed on 19 April 2016.

Eskom, 2015. Tariffs and charges: 2015/2016. Eskom Holdings SOC Limited: South Africa.

Eskom, 2016. System status briefing: January-March 2016. Available online at: http://www.eskom.co.za. Accessed on 8 June 2016.

Etzinger, A., 2013. Eskom generation and transmission expansion plans, in: proceedings for the Steel Future Conference, Sandton Sun Hotel Conference Centre, Johannesburg.

Harrison, W.J., Pearson, K.R., 1996. Computing solutions for large general equilibrium models using GEMPACK. Computational Economics. 9, 83-127. 
Horridge, J.M., 2000. ORANI-G: a general equilibrium model of the Australian economy. CoPS/IMPACT Working Paper OP-93. Centre of Policy Studies, Monash University.

Horridge, J.M., Meeraus, A., Pearson, K.R., Rutherford, T.F., 2013. Solution Software for computable general equilibrium modeling, in Dixon, P.B., Jorgenson, D.W. (Eds.), Handbook of Computable General Equilibrium Modeling.. North-Holland, Amsterdam, pp. 1331-1381.

IEA, (2015). Energy Balances of non-OECD Countries 2015. IEA, Paris. Available online at: http://0-dx.doi.org.innopac.up.ac.za/10.1787/energy bal non-oecd2015-en. Accessed on 20 April 2016.

Inglesi, R., Pouris, A., 2010. Forecasting electricity demand in South Africa: a critique of Eskom's projections. South African Journal of Science. 106(1/2), Art. \#16.

Inglesi-Lotz, R., Blignaut, J.N., 2011. Estimating the price elasticity of demand for electricity by sector in South Africa. South African Journal of Economics and Management Sciences. 14(4), 449-465.

Inglesi-Lotz, R., Blignaut, J.N., 2012a. Electricity intensities of the OECD and South Africa: a comparison. Renewable and Sustainable Energy Reviews. 16(2012), 4491-4499.

Inglesi-Lotz, R., Blignaut, J.N., 2012b. Estimating the opportunity cost of water for the Kusile and Medupi coal-fired electricity plants in South Africa. Journal of Energy in Southern Africa. 23(4), 76-85.

Inglesi-Lotz, R., Blignaut, J.N., 2014. Improving the electricity efficiency in South Africa through a benchmark-and-trade system. Renewable and Sustainable Energy Reviews. 30(2014), 833-840.

Johansen, L., 1960. A multi-sectoral study of economic growth. North-Holland, Amsterdam.

Joubert, D., 2015. Funding of investment for asset replacement and expansion of regulated infrastructure industries: theoretical criteria and parameters to ensure adequate capital, in: proceedings of the $1^{\text {st }}$ Annual Competition and Economic Regulation (ACER) Week. Southern Africa.

National Treasury, 2014. Medium Term Budget Policy Statement 2014. National Treasury, Pretoria. Published on 22 October 2014, Available online at: http://www.treasury.gov.za. Accessed on June 2015.

Roodt, D., 2014. The next ten years: the economist's perspective. Presentation delivered at the Expert Lecture Series, University of Pretoria, Pretoria, 18 November. 
Spalding-Fecher, R., Khorommbi, D., 2003. Electricity and externalities in South Africa. Energy Policy. 31(2003), 721-734.

Statistics South Africa, 2012. Energy accounts for South Africa: 2002-2009. Discussion Document D0405.1.1, Statistics South Africa, Pretoria.

Statistics South Africa, 2014. Gross domestic product, fourth quarter 2012. Statistical Release P0441, Statistics South Africa, Pretoria.

The Presidency, 2014. Twenty-year review: South Africa 1994-2014. The Presidency Republic of South Africa, Pretoria.

Winkler, H., 2007. Energy policies for sustainable development in South Africa. Energy for Sustainable Development. 11(1), 26-34. 


\section{Appendices}

Table A.1: Eskom's New Build Programme Schedule

\begin{tabular}{|c|c|c|c|c|}
\cline { 2 - 3 } \multicolumn{1}{c|}{} & \multicolumn{2}{c|}{ New Build Coal } & \multicolumn{2}{c|}{} \\
Year & $\begin{array}{c}\text { Medupi } \\
\text { (MW) } \\
(\mathbf{1})\end{array}$ & $\begin{array}{c}\text { Kusile } \\
\text { (MW) } \\
\text { (2) }\end{array}$ & $\begin{array}{c}\text { Ingula } \\
\text { (MW) }\end{array}$ & $\begin{array}{c}\text { Total } \\
\text { (MW) }\end{array}$ \\
\hline \hline 2011 & & & & 0 \\
2012 & & & & 0 \\
2013 & & & & 0 \\
2014 & 800 & & 1332 & 2132 \\
2015 & 800 & & & 3200 \\
2016 & 1600 & 1600 & & 1600 \\
2017 & 800 & 800 & & 2400 \\
2018 & 800 & 1600 & & 800 \\
2019 & & 800 & & 0 \\
2020 & & & & 0 \\
2021 & & & & 0 \\
2022 & & & & 0 \\
2023 & & & & \\
2024 & & & & \\
2025 & & & & 0 \\
2026 & & & & 0 \\
2027 & & & & 0 \\
2028 & & & & 0 \\
2029 & & & & 0 \\
2030 & & & & 0 \\
\hline Total MW & 4800 & 4800 & & 0 \\
\hline
\end{tabular}

\begin{tabular}{|c|c|}
\hline $\begin{array}{c}\text { Kusile and } \\
\text { Medupi Total } \\
\text { Extra }\end{array}$ & $\begin{array}{c}\text { Kusile and } \\
\text { Medupi \% of } \\
\text { Capacity } \\
\text { Total New) } \\
\text { Build }\end{array}$ \\
\hline \hline 9600 & 87.82 \\
\hline
\end{tabular}

Source: Adapted from Eskom (2014b, 2014d)

\begin{tabular}{|l|l|}
\hline \multirow{2}{*}{ 1) Medupi has a total capacity of $4800 \mathrm{MW}$, with 6 Units of $800 \mathrm{MW}$ each, } \\
here we are assuming that the first unit will join the power grid in December 2014, \\
with every extra unit being activated in 8 months intervals (as suggested by Eskom, 2014d) \\
2) Kusile has a total capacity of $4800 \mathrm{MW}$, with 6 units of 800MW each, \\
here we are assuming that the first unit will join the power grid in January 2016, \\
with every extra unit being activated in 8 months intervals (as suggested by Eskom, 2014d)
\end{tabular}


Figure B.1: Stylized representation of the core UPGEM database

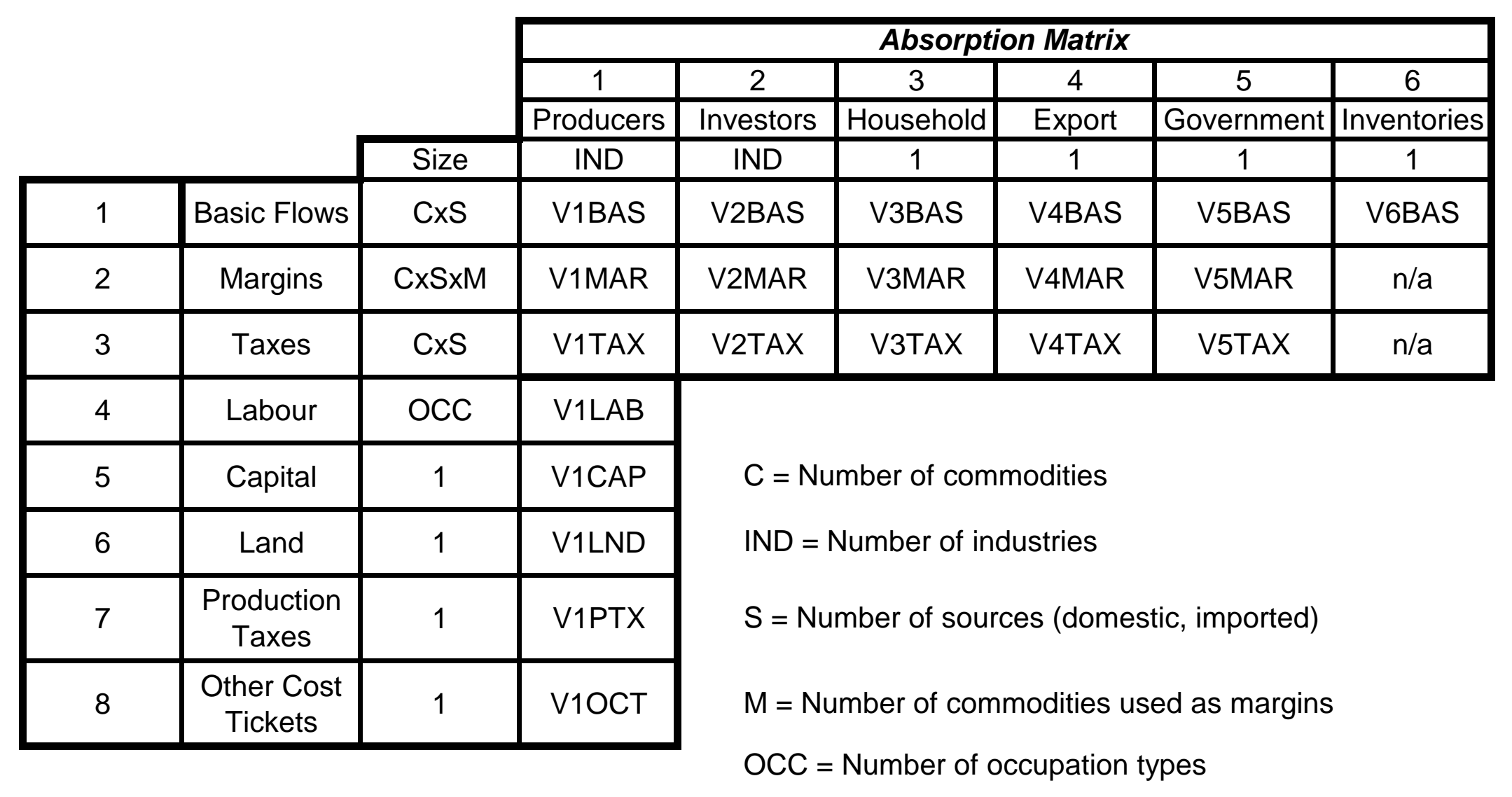
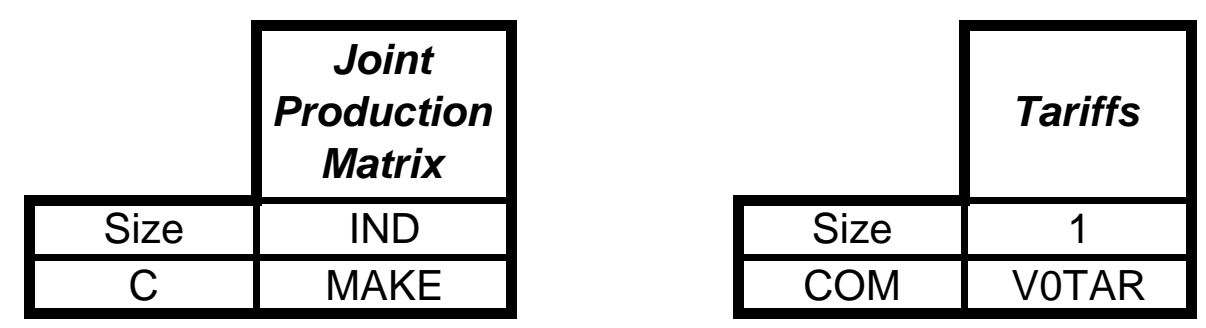

Source: Adapted from Horridge (2000) 
Figure C.1: Nested production structure in UPGEM

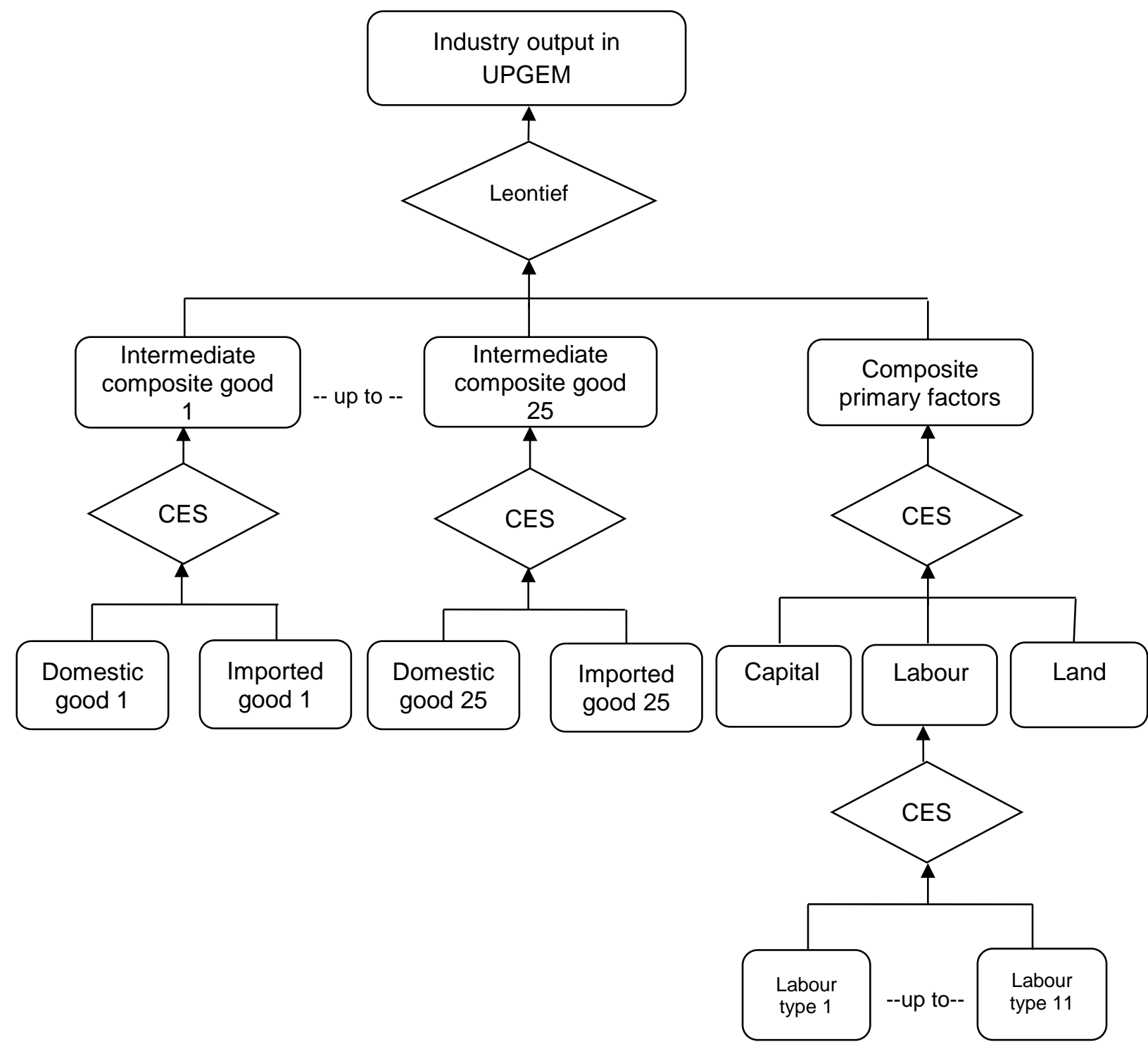

Source: Adapted from Horridge (2000) 
Table D.1: BAU baseline forecast for selected macroeconomic variables (year-on-year percentage change from 2011)

\begin{tabular}{|c|c|c|c|c|c|c|c|c|c|c|c|c|c|c|c|c|c|c|c|c|}
\hline BASE CASE MACROS (B50B-ssy) & 2012 & 2013 & 2014 & 2015 & 2016 & 2017 & 2018 & 2019 & 2020 & 2021 & 2022 & 2023 & 2024 & 2025 & 2026 & 2027 & 2028 & 2029 & 2030 & verac \\
\hline Real GDP (xogdpexp) & 2,21 & 2,13 & 1,40 & 2,50 & 2,80 & 3,00 & 3,50 & 3,50 & 3,50 & 3,50 & 3,50 & 3,50 & 3,50 & 3,50 & 3,50 & 3,50 & 3,50 & 3,50 & 3,50 & \\
\hline Real GNE (x0gne) & 4,09 & 2,96 & 2,04 & 2,37 & 2,89 & 3,10 & 3,11 & 3,10 & 3,10 & 3,12 & 3,14 & 3,16 & 3,18 & 3,21 & 3,23 & 3,25 & 3,27 & 3,28 & 3,30 & \\
\hline Households (x3tot) & 3,50 & 2,70 & 1,90 & 2,30 & 2,80 & 3,00 & 2,97 & 3,13 & 3,22 & 3,28 & 3,32 & 3,36 & 3,39 & 3,42 & 3,45 & 3,47 & 3,50 & 3,52 & 3,53 & \\
\hline ivestment (x2tot_i) & 5,70 & 3,20 & 2,70 & 3,60 & 4,70 & 5,10 & 3,69 & 3,00 & 2,70 & 2,55 & 2,46 & 2,41 & 2,37 & 2,35 & 2,34 & 2,33 & 2,32 & 2,32 & 2,32 & \\
\hline Government (x5tot) & 4,20 & 3,40 & 1,80 & 1,50 & 1,50 & 1,50 & 2,97 & 3,13 & 3,22 & 3,28 & 3,32 & 3,36 & 3,39 & 3,42 & 3,45 & 3,47 & 3,50 & 3,52 & 3,53 & \\
\hline Exports (x4tot) & 0,10 & 4,80 & $-1,22$ & 4,76 & 4,96 & 5,57 & 4,72 & 4,63 & 4,54 & 4,46 & 4,37 & 4,29 & 4,20 & 4,13 & 4,05 & 3,99 & 3,92 & 3,87 & 3,81 & \\
\hline Imports (xocif_c) & 6,30 & 7,30 & 1,00 & 4,10 & 5,00 & 5,60 & 3,47 & 3,37 & 3,33 & 3,31 & 3,30 & $3,2 \mathrm{c}$ & 3,28 & 3,27 & 3,27 & 3,26 & 3,26 & 3,25 & 3,25 & \\
\hline Capital (x1cap_i) & 1,33 & 1,62 & 1,70 & 1,76 & 1,89 & 2,12 & 2,36 & 2,46 & 2,50 & 2,51 & 2,51 & 2,51 & 2,50 & 2,48 & 2,47 & 2,46 & 2,45 & 2,44 & 2,43 & \\
\hline -abour (emp_jobs) & 50 & 0,50 & 1,00 & 2,00 & 2,00 & 2,00 & 2,00 & 2,00 & 2,00 & 2,00 & 2,00 & 2,00 & 2,00 & 2,00 & 2,00 & 2,00 & 2,00 & 2,00 & 2,00 & \\
\hline Technical Change (a_cont) & , 19 & 1,08 & $-0,06$ & 0,54 & 0,76 & 0,86 & 1,26 & 1,22 & 1,21 & 1,20 & 1,21 & 1,21 & 1,22 & 1,23 & 1,23 & 1,24 & 1,25 & 1,26 & 1,26 & \\
\hline Tax Carrying Flows (tof_cont) & 0,22 & 0,13 & 0,20 & 0,25 & 0,28 & 0,30 & 0,38 & 0,39 & 0,39 & 0,39 & 0,39 & 0,30 & 0,40 & 0,40 & 0,40 & 0,40 & 0,40 & 0,40 & 0,40 & \\
\hline Real Wage (real_wage_c) & 1,00 & 1,00 & 0,50 & 0,50 & 0,50 & 0,50 & 1,83 & 2,34 & 2,51 & 2,56 & 2,56 & 2,54 & 2,50 & 2,47 & 2,43 & 2,38 & 2,34 & 2,30 & 2,27 & \\
\hline GDP Deflator (p0gdpexp) & 5,86 & 5,10 & 6,17 & 5,55 & 5,59 & 5,46 & 5,33 & 5,53 & 5,59 & 5,61 & 5,61 & 5,61 & 5,60 & 5,60 & 5,60 & 5,59 & 5,59 & 5,58 & 5,58 & \\
\hline GNE Defflator (p0gne) & 6,56 & 5,39 & 6,15 & 5,43 & 5,61 & 5,48 & 5,35 & 5,53 & 5,59 & 5,61 & 5,61 & 5,61 & 5,60 & 5,60 & 5,60 & 5,59 & 5,59 & 5,58 & 5,58 & \\
\hline Real Devaluation (p0realdev) & 0,17 & 1,68 & $-0,59$ & 0,83 & 0,73 & 0,69 & 0,52 & 0,14 & 0,00 & $-0,05$ & $-0,07$ & $-0,07$ & $-0,07$ & $-0,06$ & $-0,05$ & $-0,04$ & $-0,02$ & $-0,01$ & 0,00 & \\
\hline Terms of Trade (potofft) & & $-0,80$ & 0,00 & 0,50 & 0,00 & 0,00 & 0,00 & 0,00 & 0,00 & 0,00 & 0,00 & $0,0 c$ & 0,00 & 0,00 & 0,00 & 0,00 & 0,00 & 0,00 & 0,00 & \\
\hline Export Price Index (p4tot) & 3,71 & 6,01 & 5,55 & 6,95 & 6,36 & 6,18 & 5,87 & 5,68 & 5,59 & 5,56 & 5,54 & 5,53 & 5,53 & 5,54 & 5,55 & 5,55 & 5,56 & 5,57 & 5,57 & \\
\hline Import Price Index (p0imp_c) & 6,04 & 6,86 & 5,55 & 6,42 & 6,36 & 6,18 & 5,87 & 5,68 & 5,59 & 5,56 & 5,54 & 5,53 & 5,53 & 5,54 & 5,55 & 5,55 & 5,56 & 5,57 & 5,57 & \\
\hline Nominal Exchange Rate (phi) & $-11,90$ & $-9,00$ & $-5,28$ & $-6,06$ & $-6,00$ & $-5,84$ & $-5,56$ & $-5,39$ & $-5,31$ & $-5,28$ & $-5,27$ & $-5,26$ & $-5,26$ & $-5,27$ & $-5,27$ & $-5,28$ & $-5,28$ & $-5,29$ & $-5,30$ & \\
\hline Consumer Price Index (p3tot) & 5,70 & 5,70 & 6,10 & 5,80 & 5,70 & 5,60 & 5,50 & 5,50 & 5,50 & 5,50 & 5,50 & 5,50 & 5,50 & 5,50 & 5,50 & 5,50 & 5,50 & 5,50 & 5,50 & \\
\hline Labour Prices (p1lab_io) & & 6,75 & 6,63 & 6,33 & 6,23 & 6,13 & 7,42 & 7,96 & 8,14 & 8,19 & 8,19 & 8,17 & 8,13 & 8,09 & 8,05 & 8,01 & 7,97 & 7,92 & 7,88 & \\
\hline Capital Rentals (p1cap_i) & 8,05 & 5,73 & 5,57 & 5,67 & 6,41 & 6,44 & 5,81 & 5,57 & 5,43 & 5,35 & 5,31 & 5,29 & 5,28 & 5,29 & 5,29 & 5,30 & 5,31 & 5,32 & 5,33 & \\
\hline Investment Prices (p2tot_i) & 7,88 & 3,27 & 6,16 & 5,63 & 6,42 & 5,92 & 4,44 & 5,00 & 5,21 & 5,31 & 5,36 & 5,30 & 5,41 & 5,43 & 5,44 & 5,44 & 5,45 & 5,45 & 5,45 & \\
\hline Change in Current Account Defii & 196,9 & 54425,8 & 47437,4 & 21457,7 & 38639,8 & 44273,3 & 25225,1 & 24167,1 & 23881,4 & 23911,9 & 24079,7 & 24295,2 & 24502,7 & 24659,6 & 24729,5 & 24678,0 & 24470,0 & 24069,2 & 23437,0 & \\
\hline Change in Foreign Debt (d_fd_t $)(\mathrm{Rm})$ & 64202,4 & 147399,0 & 201825,0 & 249262,0 & 270720,0 & 309360,0 & 353634,0 & 378858,0 & 403026,0 & 426907,0 & 450818,0 & 474898,0 & 499194,0 & 523696,0 & 548355,0 & 573085,0 & 597762,0 & 622234,0 & 646303,0 & \\
\hline Change in Interest on Foreign Debt (d_ir & 5136,2 & 11791,9 & 16146,0 & 19941,0 & 21657,6 & 24748,8 & 28290,7 & 30308,7 & 32242,1 & 34152,6 & 36065,5 & $37991, \varepsilon$ & 39935,5 & 41895,7 & 43868,4 & 45846,8 & 47821,0 & 49778,7 & 51704,2 & \\
\hline hange in Budget Deficiti (d_gov_def) (Rm) & 60366,0 & 52133,5 & 53014,3 & 22347,6 & 30168,3 & 31592,8 & 38017,2 & 48597,5 & 55054,5 & 61307,2 & 67899,4 & 75066,8 & 82929,2 & 91582,1 & 101099,0 & 111548,0 & 123016,0 & 135609,0 & 149413,0 & \\
\hline
\end{tabular}

\begin{tabular}{|c|c|c|c|c|c|c|c|c|c|c|c|c|c|c|c|c|c|c|c|c|}
\hline BASE CASE ELECTRICITY (B50B-ssy) & 2012 & 2013 & 2014 & 2015 & 2016 & 2017 & 2018 & 2019 & 2020 & 2021 & 2022 & 2023 & 2024 & 2025 & 2026 & 2027 & 2028 & 2029 & 2030 & Average \\
\hline Electricity & 0 & 1,7 & & 3,5 & 3,5 & 3,5 & 2,0 & 2,0 & 2,0 & 2,0 & 2,0 & 2,0 & 2,0 & 2,0 & 2,0 & 2,0 & 2,0 & 2,0 & & \\
\hline Electricity Prices (poind) & 16,0 & 8,0 & $8, c$ & 8,0 & 8,0 & 8,0 & 5,5 & 5,5 & 5,5 & 5,5 & 5,5 & 5,5 & 5,5 & 5,5 & 5,5 & 5,5 & 5,5 & 5,5 & & \\
\hline
\end{tabular}


Table D.2: BAU baseline forecast for selected macroeconomic variables (cumulative percentage change relative to 2011)

\begin{tabular}{|l|l|l|l|l|l|l|l|l|l|l|l|l|l|l|l|l|l|l|l|}
\hline BASE CASE MACROS (B50B-sSC) & 2012 & 2013 & 2014 & 2015 & 2016 & 2017 & 2018 & 2019 & 2020 & 2021 & 2022 & 2023 & 2024 & 2025 & 2026 & 2027 & 2028 & 2029 & 2030 \\
\hline
\end{tabular}

\begin{tabular}{|c|c|c|c|c|c|c|c|c|c|c|c|c|c|c|c|c|c|c|c|}
\hline & & & & & & & & & & & & & & & & & & & \\
\hline Real GDP (x0gdpexp) & 2,21 & 4,39 & 5,85 & 8,50 & 11,53 & 14,88 & 18,90 & 23,06 & 27,37 & 31,83 & 36,44 & 41,22 & 46,16 & 51,28 & 56,57 & 62,05 & 67,72 & 73,59 & 79 \\
\hline Real GNE (xogne) & 4,09 & 7,17 & 9,36 & 11,95 & 15,18 & 18,76 & 22,45 & 26,24 & 30,15 & 34,21 & 38,43 & 42,80 & 47,35 & 52,07 & 56,98 & 62,08 & 67,37 & 72,86 & 78,57 \\
\hline Households (x3tot) & 3,50 & 6,29 & 8,31 & 10,81 & 13,91 & 17,33 & 20,81 & 24,59 & 28,60 & 32,81 & 37,22 & 41,83 & 46,64 & 51,66 & 56,90 & 62,35 & 68,02 & 73,93 & \\
\hline Investment (x2tot_i) & 5,70 & 9,08 & 12,03 & 16,06 & 21,52 & 27,71 & 32,42 & 36,40 & 40,09 & 43,66 & 47,19 & 50,73 & 54,31 & 57,94 & 61,62 & 65,39 & 69,23 & 73,15 & \\
\hline Government (x5tot) & 4,20 & 7,74 & 9,68 & 11,33 & 13,00 & 14,69 & 18,10 & 21,80 & 25,71 & 29,83 & 34,14 & 38,65 & 43,35 & 48,26 & 53,38 & 58,70 & 64,25 & 70,03 & 76.03 \\
\hline Exports (x4tot) & 0,10 & 4,90 & 3,63 & 8,56 & 13,94 & 20,28 & 25,96 & 31,79 & 37,77 & 43,91 & 50,21 & 56,64 & 63,23 & 69,97 & 76,86 & 83,91 & 91,12 & 98,51 & \\
\hline Imports (X0cif_c) & 6,30 & 14,06 & 15,20 & 19,92 & 25,92 & 32,97 & 37,58 & 42,22 & 46,95 & 51,82 & 56,82 & 61,98 & 67,30 & 72,77 & 78,42 & 84,23 & 90,23 & 96,42 & 102,80 \\
\hline Capital (x1cap_i) & 1,33 & 2,97 & 4,72 & 6,57 & 8,59 & 10,89 & 13,51 & 16,30 & 19,20 & 22,20 & 25,27 & 28,41 & 31,61 & 34,88 & 38,21 & 41,61 & 45,07 & 48,61 & 52,21 \\
\hline Labour (emp_jobs) & 0,50 & 1,00 & 2,01 & 4,05 & 6,13 & 8,26 & 10,42 & 12,63 & 14,88 & 17,18 & 19,52 & 21,91 & 24,35 & 26,84 & 29,38 & 31,96 & 34,60 & 37,30 & 40 \\
\hline Technical Change (a_cont) & 1,19 & 2,28 & 2,22 & 2,77 & 3,56 & 4,44 & 5,77 & 7,06 & 8,35 & 9,65 & 10,98 & 12,32 & 13,69 & 15,08 & 16,50 & 17,95 & 19,42 & 20,92 & \\
\hline Tax Carrying Flows (tcf_cont) & 0,22 & 0,36 & 0,56 & 0,81 & 1,09 & 1,39 & 1,78 & 2,18 & 2,58 & 2,98 & 3,38 & 3,79 & 4,20 & 4,61 & 5,03 & 5,45 & 5,87 & 6,29 & \\
\hline Real Wage (real_wage_c) & 1,00 & 2,01 & 2,52 & 3,03 & 3,55 & 4,07 & 5,97 & 8,44 & 11,17 & 14,02 & 16,94 & 19,91 & 22,91 & 25,94 & 29,00 & 32,07 & 35,17 & 38,28 & \\
\hline GDP Deflator (p0gdpexp) & 5,86 & 11,26 & 18,13 & 24,68 & 31,65 & 38,84 & 46,23 & 54,32 & 62,95 & 72,08 & 81,74 & 91,93 & 102,69 & 114,04 & 126,02 & 138,65 & 151,98 & 166,05 & 180,8 \\
\hline GNE Deflator (p0gne) & 6,56 & 12,30 & 19,21 & 25,69 & 32,74 & 40,02 & 47,51 & 55,67 & 64,38 & 73,59 & 83,33 & 93,61 & 104,46 & 115,91 & 127,99 & 140,73 & 154,18 & 168,36 & \\
\hline Real Devaluation (p0realdev) & 0,17 & 1,85 & 1,25 & 2,09 & 2,84 & 3,55 & 4,08 & 4,23 & 4,23 & 4,18 & 4,11 & 4,03 & 3,96 & 3,90 & 3,85 & 3,81 & 3,79 & 3,78 &, 7 \\
\hline Terms of Trade (p0toft) & $-2,20$ & $-2,98$ & $-2,98$ & $-2,50$ & $-2,50$ & $-2,50$ & $-2,50$ & $-2,50$ & $-2,50$ & $-2,50$ & $-2,50$ & $-2,50$ & $-2,50$ & $-2,50$ & $-2,50$ & $-2,50$ & $-2,50$ & $-2,50$ &, 50 \\
\hline Export Price Index (p4tot) & 3,71 & 9,94 & 16,04 & 24,11 & 32,01 & 40,17 & 48,40 & 56,82 & 65,59 & 74,79 & 84,47 & 94,68 & 105,45 & 116,83 & 128,86 & 141,56 & 154,99 & 169,19 & \\
\hline Import Price Index (p0imp_c) & 6,04 & 13,31 & 19,60 & 27,28 & 35,38 & 43,74 & 52,18 & 60,82 & 69,81 & 79,25 & 89,18 & 99,64 & 110,69 & 122,36 & 134,70 & 147,73 & 161,50 & 176,06 & 191 \\
\hline Nominal Exchange Rate (phi) & $-11,90$ & $-19,83$ & $-24,06$ & $-28,66$ & $-32,94$ & $-36,86$ & $-40,37$ & $-43,59$ & $-46,59$ & $-49,41$ & $-52,07$ & $-54,59$ & $-56,98$ & $-59,25$ & $-61,39$ & $-63,43$ & $-65,36$ & $-67,20$ & $-68,93$ \\
\hline Consumer Price Index (p3tot) & 5,70 & 11,72 & 18,54 & 25,42 & 32,56 & 39,99 & 47,69 & 55,81 & 64,38 & 73,42 & 82,96 & 93,02 & 103,64 & 114,84 & 126,65 & 139,12 & 152,27 & 166,15 & 180,78 \\
\hline Labour Prices (p1lab_io) & 6,75 & 13,96 & 21,52 & 29,21 & 37,25 & 45,66 & 56,47 & 68,92 & 82,67 & 97,64 & 113,83 & 131,30 & 150,12 & 170,36 & 192,12 & 215,51 & 240,65 & 267,64 & 296,6 \\
\hline Capital Rentals (p1cap_i) & 8,05 & 14,23 & 20,59 & 27,43 & 35,59 & 44,32 & 52,70 & 61,20 & 69,96 & 79,05 & 88,56 & 98,53 & 109,02 & 120,07 & 131,72 & 144,00 & 156,96 & 170,63 & 185 \\
\hline Investment Prices (p2tot_i) & 7,88 & 11,40 & 18,27 & 24,92 & 32,94 & 40,81 & 47,05 & 54,40 & 62,45 & 71,07 & 80,25 & 89,97 & 100,25 & 111,12 & 122,60 & 134,72 & 147,51 & 161,00 & 175,2 \\
\hline Change in Current Account Deficit (d_cad) (Rm) & 83196,9 & 137623,0 & 185060,0 & $206518,0 \mid$ & 245158,0 & 289431,0 & 314656,0 & 338823,0 & 362704,0 & 386616,0 & 410696,0 & 434991,0 & 459494,0 & 484154,0 & \begin{tabular}{l|l|l|}
0 & 508883,0 \\
\end{tabular} & 533561,0 & $\mid 558031,0$ & 582100,0 & 605537,0 \\
\hline Change in Foreign Debt $\left(\mathrm{d} \_\right.$_d $\_$t $)(\mathrm{Rm})$ & 64202,4 & 211602,0 & 413427,0 & 662689,0 & 933410,0 & 1242770,0 & 1596403,0 & 1975262,0 & $|2378288,0|$ & 2805195,0 & 3256013,0 & $\mid 3730911,0$ & 4230105,0 & 4753801,0 & 05302156,0 & 5875241,0 & 6473004,0 & 7095237,0 & 7741540 \\
\hline Change in Interest on Foreign Debt (d_int_fd) (R & 5136,2 & 16928,1 & 33074,1 & 53015,1 & 74672,8 & 99421,6 & $\mid 127712,0$ & 158021,0 & 190263,0 & 224416,0 & 260481,0 & 298473,0 & 338408,0 & 380304,0 & 0424173,0 & 470019,0 & 517840,0 & 567619,0 & 619323,0 \\
\hline Change in Budget Deficit (d_gov_def) (Rm) & 60366,0 & 112500,0 & $\mid 165514,0$ & 187862,0 & 218030,0 & $\mid 249623,0$ & 287640,0 & $\mid 336237,0$ & $\mid 391292,0$ & 452599,0 & 520499,0 & 595565,0 & 678494,0 & 770077,0 & \begin{tabular}{l|l|}
0 & 871176,0 \\
\end{tabular} & 982724,0 & 1105740,0 & 1241348,0 & 139076 \\
\hline
\end{tabular}

\begin{tabular}{|c|c|c|c|c|c|c|c|c|c|c|c|c|c|c|c|c|c|c|c|}
\hline BASE CASE ELECTRICITY (B50B-sSC) & 2012 & 2013 & 2014 & 2015 & 2016 & 2017 & 2018 & 2019 & 2020 & 2021 & 2022 & 2023 & 2024 & 2025 & 2026 & 2027 & 2028 & 2029 & 2030 \\
\hline Electricity Output (xOind) & 0,3 & 1,9 & 5,0 & 8,7 & 12,5 & 16,4 & 18,8 & 21,1 & 23,5 & 26,0 & 28,5 & 31,1 & 33,7 & 36,4 & 39,1 & 41,9 & 44,8 & 47,7 & 50,6 \\
\hline Electricity Prices (p0ind) & 16,0 & 25,3 & 35,3 & 46,1 & 57,8 & 70,4 & 79,8 & 89,7 & 100,1 & 111,1 & 122,8 & 135,0 & 147,9 & 161,6 & 176,0 & 191,1 & 207,2 & 224,0 & 241,9 \\
\hline
\end{tabular}

Source: UPGEM (GEMPACK) and Author's Own Calculations 